\title{
Excitation of Transient Waves by Localized Episodic Heating in the Tropics and Their Propagation into the Middle Atmosphere
}

\author{
By Takeshi Horinouchi and Shigeo Yoden \\ Department of Geophysics, Kyoto University, Kyoto 606-01, Japan \\ (Manuscript received 25 April 1995, in revised form 11 December 1995)
}

\begin{abstract}
Response of a resting spherical atmosphere to transient localized heating in the tropics is studied theoretically with linearized primitive equations. The method of separation of variables is used to solve the problem, and time-integrations of the full nonlinear equations are also done to assess the linearity of the response.

The linearity of the response is good for some realistic values of the heating. The dominant responses are equatorially-trapped vertically propagating waves whose vertical scale matches that of the heating and global normal (or free) modes. In the middle atmosphere, the equatorially trapped waves respond effectively if the angular frequency is the order of $10 \times$ [damping rate]. If the frequency is greater than this order, the response is suppressed in a stochastic sense; while if the frequency is less than this order, it is suppressed by the damping.

Spatial pattern of the response is obtained for a realization of idealized stochastic heating with a Gaussian form in space and time. For the heating, of which the time scale is a few days or longer, horizontal cross sections of the response show the "Gill pattern" at the beginning and then the response disperses zonally in low latitudes. For short-lived heating, on the other hand, the gravity wave response expands concentrically at the beginning and then the response spreads zonally in low latitudes.

Energy and momentum spectra to various kinds of wave are calculated for the stochastic heating. As the time scale of the heating events decreases, gravity-wave responses increase relatively to Rossby-wave responses. As the zonal scale of the heating events decreases, on the other hand, Rossby-wave responses slightly increase relatively to the gravity-wave responses. Heating just on the equator is less effective to excite Rossby waves than that off the equator. Energy and momentum of these vertically propagating waves are of comparable orders to those of the real atmosphere if the heating has an appropriate spectrum with a realistic amount comparable to the total latent heat release in the tropics; and so does the energy of global normal modes.

Wave energy propagation into the middle atmosphere has to be taken into account even for the calculation of the transient response in the troposphere if the dominant frequency is larger than the damping rate.
\end{abstract}

\section{Introduction}

Various kinds of wave motion have been observed since the 1960's in the equatorial middle atmosphere. Both Rossby-gravity waves (Yanai and Maruyama, 1966) and Kelvin waves (Wallace and Kousky, 1968a) were found in the equatorial lower stratosphere using conventional radiosonde data. Kelvin waves with higher frequencies than those in the lower stratosphere were found in the upper stratosphere by Hirota (1978) using rocket observation data. There are also some observations of other waves such as global Rossby normal modes (e.g., Yanai and Lu, 1983) and inertio-gravity waves

(C)1996, Meteorological Society of Japan (e.g., Tsuda et al., 1994).

The primary source of these vertically propagating equatorial waves has been considered to be in cumulus convective systems in the tropical troposphere. There are three approaches to investigate the excitation of these waves.

In the first approach, the response of the atmosphere to externally specified heating has been studied; the heating is assumed to be the release of latent heat in cumulus convective systems. Holton (1972) investigated the linear response to localized and oscillating thermal forcing, and showed that some particular combinations of forcing and background wind can generate Kelvin waves and Rossby-gravity waves in the lower stratosphere. Holton (1973) related the 
observed frequency distribution of Kelvin waves to a vertical wavelength selection determined by the vertical structure of the heating. On the other hand, Hayashi (1976) investigated this selected response and called it "non-singular resonance". Itoh (1977) related the observed zonal wavenumber distribution of Kelvin and Rossby-gravity waves to a frequency selection of the responses. While these studies were done on the equatorial $\beta$-plane with sinusoidally oscillating thermal forcing, Salby and Garcia (1987, hereafter referred to as SG) studied linear responses of a resting spherical atmosphere to stochastic thermal forcing. They showed that the dominant responses are not only the vertically propagating equatorial waves but also global normal modes. They also showed some examples of the time evolution of geopotential height response ("cardinal response"). Garcia and Salby (1987, hereafter GS) extended their study (SG) to the propagation of these waves away from the forcing region using a climatological basic state. Bergman and Salby (1994) calculated the linear response to heating estimated observationally from satellite global cloud imagery. They showed that the energy spectrum of the response is red but the spectrum of the Eliassen-Palm (EP) flux is whiter than this; $75 \%$ of the EP flux transmitted to the stratosphere is carried by waves of zonal wavenumber 20 or greater.

In the second approach, the heating is not specified externally but determined internally by a cumulus parameterization. The linear growth of equatorial waves under the wave-CISK(Conditional Instability of the Second Kind) mechanism was originally investigated by Hayashi (1970), while timespace wave analysis for an equilibrium state obtained with a General Circulation Model (GCM) has been done by many authors, including Hayashi and Golder (1978). In a GCM, not only cumulus heating but other factors may cause or affect wave excitation. Hayashi and Golder (1978) concluded that latent heat release due to cumulus convection is the dominant cause of Kelvin wave excitation, while a certain combination of the latent heat release and mid-latitude disturbances is that of Rossby-gravity wave excitation.

In the third approach, lateral forcing by midlatitude disturbances is assumed for the excitation of equatorial waves, particularly Rossby-gravity waves (e.g., Mak, 1969). Some observational studies seem to support this mechanism for Rossby-gravity wave excitation (Zangvil and Yanai, 1980; Magaña and Yanai, 1991,1995). Lateral forcing may play some role in the excitation in cooperation with cumulus convection. However, it is not enough to account for the total equatorial wave excitation.

Recently, Manzini and Hamilton (1993, hereafter $\mathrm{MH}$ ) compared the statistics of equatorial waves simulated in the GFDL SKYHI GCM with those simulated in a linearized primitive model in which the forcing is the latent and convective heating obtained from the GCM. The linear model reproduced Kelvin, Rossby-gravity, and inertio-gravity waves with similar amplitude to those in the GCM (the difference was less than a factor of 2). Thus they concluded that the heating is the dominant source that produced these waves. Their result suggests that once the heating in the equatorial troposphere is specified, the feedback mechanism from large-scale dynamics to cumulus convections (or some phase lock between large-scale dynamics and cumulus convections) has only a small influence on the excitation of waves that propagate into the middle atmosphere. Hence, it would be justified to investigate the excitation of waves in the middle atmosphere as a response to prescribed heating.

The simplest approach to explain the excitation of equatorial waves is the first one. Knowledge on wave excitation by localized heating has been accumulated for two decades. However, it is still uncertain to what extent this theory is applicable to the equatorial waves observed in the middle atmosphere. This is partly because we still do not know in detail what kind and what amount of response will result from a given profile of heating. In the present paper, we focus on the basic feature of this excitation mechanism so that we can get insight into the relationship between the heating and the response.

As for global normal modes, $\mathrm{MH}$ showed that amplitudes in the linear model are much smaller than those in the GCM; that is, the linear response to heating in the tropics is not sufficient to explain the normal modes obtained in the GCM. On the other hand, SG emphasized that heating in the tropics excites normal modes. It is not clear whether these two results conflict òr not, since no quantitative description was given in SG. The excitation of global normal modes by the localized heating in the tropics is another subject investigated in this work.

The mathematical formulation is described in Section 2. Section 3 gives an analytical argument on the excitation, where the general feature of the response is elucidated mainly with the separated vertical structure equations. Section 4 gives some numerical results including flow patterns induced by the heating and distributions of energy and momentum on various kinds of wave, in terms of the dependence on heating parameters. Discussion follows in Section 5, including an application to the real atmosphere with some order estimation. Conclusions are given in Section 6.

\section{Basic equations and the method of sepa- ration of variables}

We use linearized primitive equations in a spherical geometry with a log-pressure vertical coordinate $z \equiv-H \ln \left(p / p_{s}\right)$, where $p$ is pressure, $p_{s}$ is a 
standard reference pressure which is approximately equal to surface pressure, and $H$ is a constant scale height set equal to $7 \mathrm{~km}$. The basic state we assume is at rest, and the buoyancy frequency $N$ is a function only of $z$. The Newtonian cooling with a coefficient $\alpha$ is the only dissipative term in the present system.

The linearized momentum and continuity equations are

$$
\begin{aligned}
\frac{\partial u}{\partial t}-2 \Omega \sin \varphi v+\frac{\partial \Phi^{\prime}}{a \cos \varphi \partial \lambda} & =0, \\
\frac{\partial v}{\partial t}+2 \Omega \sin \varphi u+\frac{\partial \Phi^{\prime}}{a \partial \varphi} & =0 \\
\frac{\partial u}{a \cos \varphi \partial \lambda}+\frac{\partial(v \cos \varphi)}{a \cos \varphi \partial \varphi}+\frac{\partial\left(e^{-z / H} w\right)}{e^{-z / H} \partial z} & =0,
\end{aligned}
$$

where $u$ and $v$ are eastward and northward velocities, respectively, $w \equiv D z / D t, \Phi^{\prime}$ is geopotential deviation from the basic state, $t$ is time, $\lambda$ and $\varphi$ are longitude and latitude, respectively, $a$ is the radius of the earth, and $\Omega$ is the angular frequency of earth's rotation. The linearized thermodynamic energy equation is

$$
\left(\frac{\partial}{\partial t}+\alpha\right) \frac{\partial \Phi^{\prime}}{\partial z}+N^{2} w=\kappa J / H
$$

where $J$ is the heating rate, and $N^{2} \equiv$ $\frac{R}{H}\left(\frac{d T_{0}}{d z}-\frac{\kappa T_{0}}{H}\right)$, where $T_{0}(z)$ is the basic state temperature, and $\kappa \equiv R / C_{p}$.

A linearized free slip condition without topography is assumed at the lower boundary, while the radiation condition is assumed at the upper boundary.

The method of separation of variables is used to calculate the response to heating as done by SG. The equations for the horizontal and time structure are identical to homogeneous Laplace's tidal equations. Eigensolutions of the equations expressing the meridional profiles of geopotential deviation are called Hough functions, which form a complete orthogonal set for any given combination of zonal wavenumber and frequency. The dispersion relation and meridional structure of the functions are given by Longuet-Higgins (1968).

The heating term $J$ is expanded by Hough functions:

$J=e^{\zeta / 2} \sum_{s, n} \int_{-\infty}^{\infty} \mathcal{J}_{s n}^{\omega}(\zeta) \Theta_{s n}^{\omega}(\varphi) \exp i(s \lambda-\omega t) d \omega$,

where $\zeta \equiv z / H$, and $\Theta_{s n}^{\omega}(\varphi)$ is the $n$-th Hough function of angular frequency $\omega$ and zonal wavenumber $s$; note that $\mathcal{J}_{s n}^{\omega}$ is complex. In this study, Hough functions are normalized so that

$$
\int_{-\pi / 2}^{\pi / 2} \Theta_{s n}^{\omega}(\varphi)^{2} \cos \varphi d \varphi=2
$$

Zonal and meridional velocities, geopotential deviation, and vertical velocity are also expanded as follows:

$$
\begin{aligned}
& {\left[u, v, \Phi^{\prime}\right]=e^{\zeta / 2} \sum_{s, n} \int_{-\infty}^{\infty} \mathcal{U}_{s n}^{\omega}(\zeta)} \\
& {\left[\hat{u}_{s n}^{\omega}(\varphi), \hat{v}_{s n}^{\omega}(\varphi), \Theta_{s n}^{\omega}(\varphi)\right] \exp i(s \lambda-\omega t) d \omega,(7)} \\
& w / H=e^{\zeta / 2} \sum_{s, n} \int_{-\infty}^{\infty} \mathcal{W}_{s n}^{\omega}(\zeta) \hat{w}_{s n}^{\omega}(\varphi) \exp i(s \lambda-\omega t) d \omega
\end{aligned}
$$

where $\hat{u}_{s n}^{\omega}$ and $\hat{v}_{s n}^{\omega}$ are related to $\Theta_{s n}^{\omega}$ through Laplace's tidal equations, and $\hat{w}_{s n}^{\omega} \equiv-i \omega\left(g h_{s n}^{\omega}\right)^{-1}$ $\Theta_{s n}^{\omega}$, where $h_{s n}^{\omega}$ is the eigenvalue of the equations called equivalent depth. Then the vertical structure equations are written as follows:

$$
\begin{aligned}
& (1+i \alpha / \omega)\left(\frac{d^{2} \mathcal{W}_{s n}^{\omega}(\zeta)}{d \zeta^{2}}-\frac{\mathcal{W}_{s n}^{\omega}(\zeta)}{4}\right) \\
& +\frac{N^{2} H^{2}}{g h_{s n}^{\omega}} \mathcal{W}_{s n}^{\omega}(\zeta)=\frac{i \kappa \mathcal{J}_{s n}^{\omega}(\zeta)}{\omega} \\
& \mathcal{U}_{s n}^{\omega}(\zeta)=d \mathcal{W}_{s n}^{\omega}(\zeta) / d \zeta-\mathcal{W}_{s n}^{\omega}(\zeta) / 2
\end{aligned}
$$

where $g$ is the magnitude of the gravity acceleration set equal to $9.8 \mathrm{~m} / \mathrm{s}^{2}$. Since the temperature deviation is related to the geopotential deviation as $T^{\prime}=$ $(1 / R) \partial \Phi^{\prime} / \partial \zeta$, it is also expanded as follows:

$$
\begin{gathered}
T^{\prime}=e^{\zeta / 2} \sum_{s, n} \int_{-\infty}^{\infty} \mathcal{T}_{s n}^{\omega}(\zeta) \Theta_{s n}^{\omega}(\varphi) \exp i(s \lambda-\omega t) d \omega \\
\mathcal{T}_{s n}^{\omega}(\zeta) \\
\quad=d \mathcal{U}_{s n}^{\omega}(\zeta) / d \zeta+\mathcal{U}_{s n}^{\omega}(\zeta) / 2 \\
=d^{2} \mathcal{W}_{s n}^{\omega}(\zeta) / d \zeta^{2}-\mathcal{W}_{s n}^{\omega}(\zeta) / 4
\end{gathered}
$$

which will be used in Section 4 to compute the wave energy.

The lower boundary condition linearized at $\zeta=0$ is

$$
\frac{d \mathcal{W}_{s n}^{\omega}(0)}{d \zeta}+\left(\frac{R T_{0}(0)}{g h_{s n}^{\omega}}-\frac{1}{2}\right) \mathcal{W}_{s n}^{\omega}(0)=0
$$

While, the upper boundary condition is the radiation condition (i.e., upward group velocity) or the evanescent condition $(|\mathcal{W}| \rightarrow 0$ as $\zeta \rightarrow \infty)$.

One of the greatest advantage of the present method is that we can separately discuss the response of each Hough mode, or each type of wave such as Kelvin, Rossby, Rossby-gravity, and inertiogravity waves. It enables us to hold quantitative discussion on each of the wave responses, depending on the external parameters of the heating term.

Throughout this paper, the thermal structure of the basic state is set to have an idealized troposphere and a middle atmosphere with constant $N$ in each layer. In the troposphere below $\zeta_{T} \equiv 1.5, T_{0}$ is determined so that $N$ is a constant with the surface 


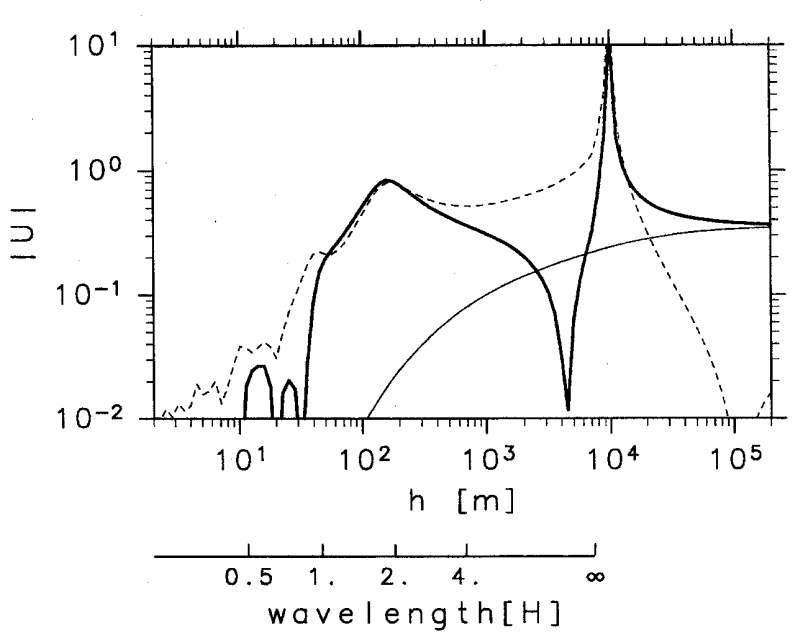

Fig. 1. $|\mathcal{U}|$ as a function of $h$ for positive $h$ at $\zeta=2$ (thick solid line) and at $\zeta=0.1$ (thin dashed line), and that for negative $h$ at $\zeta=2$ (thin solid line). Shown under the abscissa is the vertical wavelength of vertically propagating waves of positive $h$ calculated with $N$ of the middle atmosphere [Eq. (14)].

temperature $T_{0}(0)=220 \mathrm{~K}$, while $T_{0}$ in the middle atmosphere above $\zeta_{T}$ is set equal to a constant of $220 \mathrm{~K}$. Then $N$ s of the two layers are given by

$$
\begin{aligned}
& N^{2} H^{2}=\frac{R d T_{0}}{d \zeta}-\kappa R T_{0} \\
& \equiv \begin{cases}0.73 \times 10^{4} \mathrm{~m}^{2} \mathrm{~s}^{-2} & \text { for } 0<\zeta \leq \zeta_{T} \equiv 1.5, \\
1.80 \times 10^{4} \mathrm{~m}^{2} \mathrm{~s}^{-2} & \text { for } \zeta_{T}<\zeta\end{cases}
\end{aligned}
$$

so that $2 \pi / N$ is $515 \mathrm{~s}$ below $\zeta_{T}$ and $328 \mathrm{~s}$ above $\zeta_{T}$. Then $T_{0}$ below $\zeta_{T}$ is roughly linear with $\zeta$. Note that $N$ is different from the local buoyancy frequency by the factor of $H^{*} / H$, where $H^{*} \equiv R T_{0}(\zeta) / g$ is the local scale hight.

Since the middle atmosphere has a larger static stability than that of the troposphere, waves excited in the troposphere are partially reflected at the tropopause at $\zeta_{T}$ and incident waves into the middle atmosphere have smaller vertical wavelengths than those in the troposphere.

\section{Basic features of the excitation}

a. The solution of the vertical structure equation

First, basic features of the solution of the vertical structure equation (9) are investigated under some crude assumptions. Dependence of the amplitude on $h$ is examined for the non-dissipative case of $\alpha=0$ by eliminating a factor $i \kappa / \omega$ in the right hand side of Eq. (9):

$$
\frac{d^{2} \mathcal{W}}{d \zeta^{2}}-\left(\frac{1}{4}-\frac{N^{2} H^{2}}{g h}\right) \mathcal{W}=\mathcal{J}
$$

where the suffixes are omitted. The vertical structure of the heating is assumed as follows, as in GS:

$$
e^{\zeta / 2} \mathcal{J} \equiv \begin{cases}J_{0} \sin \left(\pi \zeta / \zeta_{T}\right), & \text { for } 0<\zeta \leq \zeta_{T} \\ 0, & \text { for } \zeta_{T}<\zeta\end{cases}
$$

which has a maximum in the mid troposphere. The coefficient $J_{0}$ is set equal to 1 in this section.

From Eqs. (10), (15) and (16), $|\mathcal{U}|$, the absolute value of $\mathcal{U}$ at a given $\zeta$ is obtained as a function of $h$. The thick line in Fig. 1 shows the dependence of $|\mathcal{U}|$ on $h$ in the middle atmosphere. Note that $|\mathcal{U}|$ of vertically propagating waves is uniform with height throughout the middle atmosphere because Eq. (15) has no dissipation. There are two dominant responses, as those obtained by SG; one is a sharp response corresponding to normal (or free) modes of $h \sim 10 \mathrm{~km}$ and the other is a wide response around $h \sim 200 \mathrm{~m}$. The latter has non-dimensional vertical wavelengths of around $2(2 \mathrm{H}$ in the log-pressure coordinate) in the middle atmosphere. If the basic state is isothermal, a projection response whose vertical wavelength is about twice the depth of the heating is dominant (Hayashi, 1976), i.e., the nondimensional wavelength is about $3\left(=2 \zeta_{T}\right)$. However, since $N^{2}$ of the middle atmosphere is 2.5 times as large as that of the troposphere, the dominant wavelength in the middle atmosphere is reduced to $1 / \sqrt{2.5} \simeq 1 / 1.6$ of that in the troposphere.

The thin dashed line in Fig. 1 shows $|\mathcal{U}|$ at $\zeta=0.1$. There is no sharp gap around $h \sim 5 \mathrm{~km}$ as is seen at $\zeta=2$. On the other hand, the response for negative $h$ has no conspicuous peak, as shown by a thin solid line in Fig. $1(|\mathcal{U}|$ at $\zeta=2)$.

If the heating is not smooth in the vertical, higher harmonics of the vertically propagating responses are increased. However, the response around $h \sim$ $200 \mathrm{~m}$ is still dominant. In general, the vertical profile of the heating is not important, while the depth of the heating has a large influence on the response (SG, see also Subsection $5 \mathrm{~b}$ ).

As the next step, dependence of the amplitude of the response on frequency $\omega$ is examined. Itoh (1977) examined this dependence to some extent, but in his qualitative discussion he did not incorporate the effect of dissipation that plays an important role, as shown in the following.

Equation (9) has two terms which include $\omega$ : the Newtonian cooling term in the first brackets and the forcing term divided by $\omega$ in the right hand side. If the right hand side of Eq. (9) is multiplied by $(i \kappa)^{-1} \alpha$ for analytical simplicity, then the following equation is obtained:

$\left(1+i \tilde{\omega}^{-1}\right)\left(\frac{d^{2} \mathcal{W}(\zeta)}{d \zeta^{2}}-\frac{\mathcal{W}(\zeta)}{4}\right)+\frac{N^{2} H^{2}}{g h} \mathcal{W}(\zeta)=\frac{\mathcal{J}(\zeta)}{\tilde{\omega}}$

where $\tilde{\omega} \equiv \omega / \alpha$, and the suffixes are omitted.

Figure 2a shows $|\mathcal{U}|$ derived from Eqs. (10), (16) and (17) as a function of $\tilde{\omega}$ for $h=200 \mathrm{~m}$ at $\zeta=0.1$, 2.0, 4.5 and 7.0. As mentioned above, waves around 
(a)

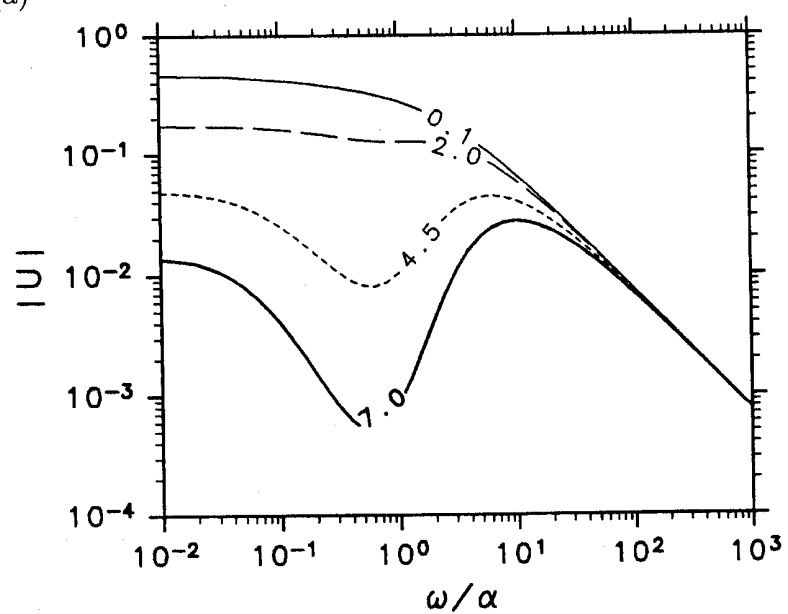

(b)

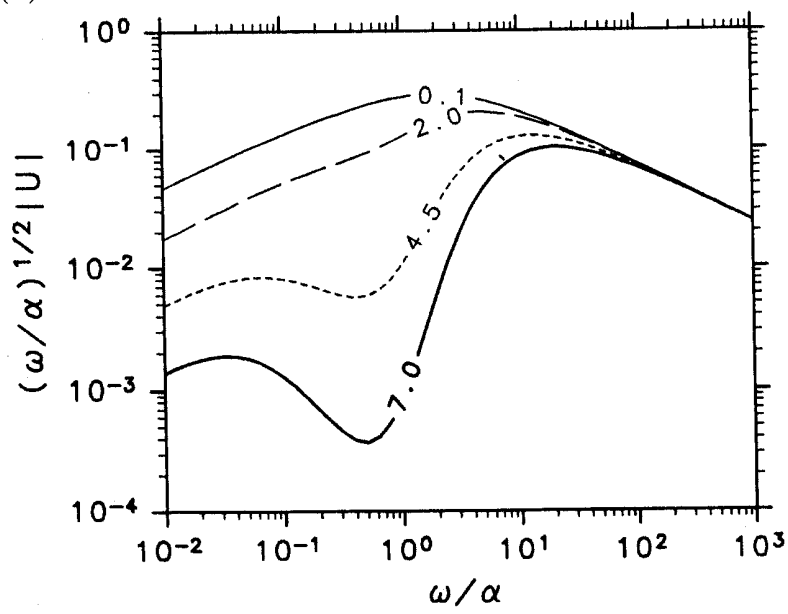

Fig. 2. (a) $|\mathcal{U}|$ as a function of $\tilde{\omega}$ with $h=200 \mathrm{~m}$. The number on each line denotes the altitude $\zeta$. (b) As in (a), but for $\tilde{\omega}^{1 / 2}|\mathcal{U}|$ (see Section 3c).

$h=200 \mathrm{~m}$ are vertically propagating and favorably excited by the tropospheric heating. If $\tilde{\omega}$ is large enough, $|\mathcal{U}|$ is proportional to $\tilde{\omega}^{-1}$ at all heights. This is the direct consequence of the forcing term being divided by $\tilde{\omega}$; as the frequency becomes lower, heating lasts for a longer period and thus the response has a larger amplitude. The amplitude $|\mathcal{U}|$ decreases with height for a given $\tilde{\omega}$ because of the dissipation term in the left-hand side of Eq. (17). The attenuation rate is larger for smaller $\tilde{\omega}$, since the dissipation term is proportional to $\tilde{\omega}^{-1}$. However, this attenuation rate becomes smaller for further small $\tilde{\omega}(<0.5)$, and $|\mathcal{U}|$ tends to be independent of $\tilde{\omega}$, since Eq. (17) can be approximated by $i \tilde{\omega}^{-1}\left(d^{2} \mathcal{W}(\zeta) / d \zeta^{2}-\mathcal{W}(\zeta) / 4\right)=\mathcal{J}(\zeta) \tilde{\omega}^{-1}$ for sufficiently small $\tilde{\omega}$. Furthermore, in this limit Eq. (17) is independent of $h$ and the vertical wavelength of the solution is infinity. This corresponds to the "viscous mode" pointed out by Chang (1977) who investigated Kelvin waves with the assumption of the

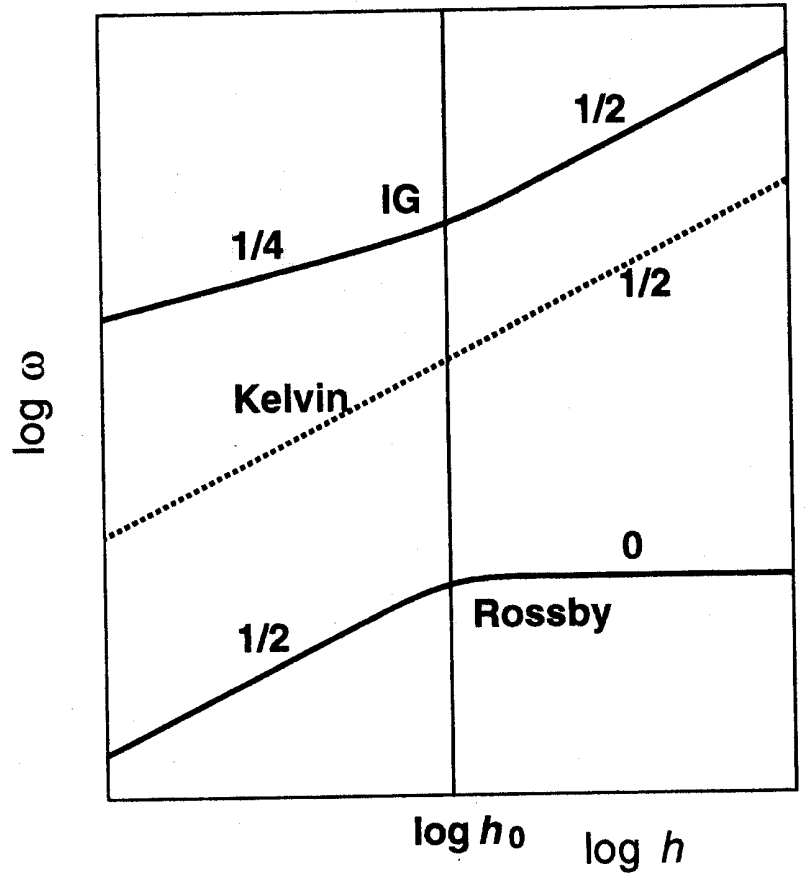

Fig. 3. Schematic illustration of the relationship between $\ln |\omega|$ and $\ln h$ for Hough modes of positive equivalent depth for a given zonal wavenumber s. Number(s) on each line denotes the inclination $\frac{d \ln |\omega|}{d \ln h} . \quad h_{0}=\beta^{2} a^{4} /\left(g s^{4}\right)$, where $a$ is the radius of the earth. Eastward-moving Rossby-gravity waves are similar to inertio-gravity (IG) waves while westward-moving Rossby-gravity waves similar to Rossby waves but for the inclination of $1 / 4$ for small $h$ (not shown).

same rate of Newtonian cooling and Rayleigh friction.

Figure $2 \mathrm{~b}$, which shows $\tilde{\omega}^{1 / 2}|\mathcal{U}|$ as a function of $\tilde{\omega}$, is used in Subsection 3c.

\section{b. Dispersion relation of Hough functions}

The horizontal and time structure of heating is transformed into a set of the coefficients $\mathcal{J}_{s n}^{\omega}(\zeta)$ through the expansion by the Hough harmonic basis Eq. (5). For each combination of zonal wavenumber $s$ and frequency $\omega$, equivalent depths $h_{s n}^{\omega}$ and Hough functions $\Theta_{s n}^{\omega}(\varphi)$ are obtained by solving an eigenproblem of the Laplace's tidal equation. As shown in the previous subsection, the important modes as responses are the evanescent modes of $h \sim 10 \mathrm{~km}$ and the vertically propagating modes around $h \sim 200 \mathrm{~m}$. Hough functions for the former show global structures, while those for the latter are trapped near the equator; the meridional scale of the latter is characterized by the equatorial radius of deformation:

$$
l_{e} \equiv(g h)^{1 / 4} \beta^{-1 / 2},
$$



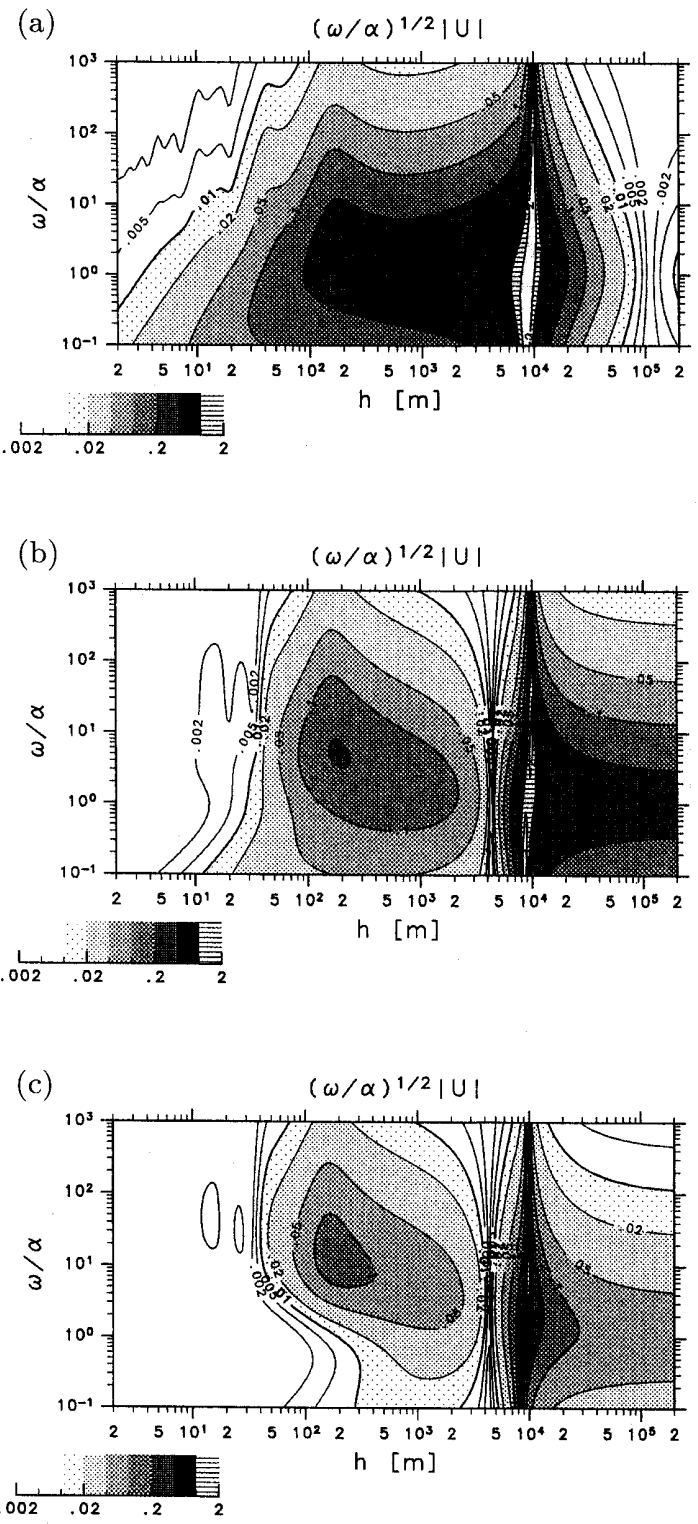

Fig. 4. $\tilde{\omega}^{1 / 2}|\mathcal{U}|$ as functions of $h$ and $\tilde{\omega}$ at (a) $\zeta=0.1$, (b) $\zeta=2.0$, and (c) $\zeta=4.5$. Note that contour interval uses a logarithmic scale.

which is about $2000 \mathrm{~km}$ for $h=200 \mathrm{~m}$, where $\beta \equiv$ $2 \Omega / a$. On the other hand, waves of $h<0$ have large amplitude near the poles, so that they have small importance as responses to the heating near the equator.

Figure 3 schematically illustrates the relationship between $\ln |\omega|$ and $\ln h$ for several Hough modes of positive equivalent depth for a given zonal wavenumber (see Longuet-Higgins (1968), or Fig. $5)$. The Hough modes are classified into Rossby waves, inertio-gravity waves (IG) and Kelvin waves (Rossby-gravity waves are not shown; see the figure caption). Each type of these waves has an almost linear relationship with a different gradient, $\frac{d \ln |\omega|}{d \ln h}$, if $h$ is sufficiently larger or smaller than $h_{0}$. Here $h_{0} \equiv \beta^{2} a^{4} /\left(g s^{4}\right)$ denotes the value of $h$ for which the zonal wavelength is equal to $2 \pi l_{e}$.

This relationship suggests that $\tilde{\omega}^{1 / 2}|\mathcal{U}|$ rather than $|\mathcal{U}|$ is useful as a measure of the solution of the vertical structure equations for the following reason. We can evaluate the magnitude of waves by squared amplitude of a quantity $A$ integrated over time, or over frequency from Perseval's equation. However, it is useful for a qualitative argument to translate the integration with $\omega$ into that with $h$, because the response depends on $h$ more sharply than $\omega$, as will be shown in the next subsection. Since $\int A^{2} d \omega=\int \omega A^{2} \frac{d \ln |\omega|}{d \ln |h|} d \ln |h|$, the frequencyintegrated energy of a mode is approximately proportional to $\omega\left(A_{s n}^{\omega}\right)^{2} \frac{d \ln |\omega|}{d \ln \left|h_{s n}^{\omega}\right|}$ over a small range of $h$, where $\frac{d \ln |\omega|}{d \ln \left|h_{s n}^{\omega}\right|}$ tends to be a constant. Thus $\tilde{\omega}|\mathcal{U}|^{2}$, or $\tilde{\omega}^{1 / 2}|\mathcal{U}|$ is a good measure of the projection from the heating to the response. Note that this corresponds to the energy content form in spectral analyses.

\section{c. Reconsideration of the solution of the vertical structure equations}

Figure $2 \mathrm{~b}$ is similar to Fig. 2a but for $\tilde{\omega}^{1 / 2}|\mathcal{U}|$, according to the discussion in the previous subsection. The frequencles at which this quantity has a maximum increases with height: $\tilde{\omega} \sim 1$ at $\zeta=0.1$, $\tilde{\omega} \sim 5$ at $\zeta=2$, and $\tilde{\omega} \sim 20$ at $\zeta=7$. In addition, a diagram of $\tilde{\omega}^{1 / 2}|\mathcal{T}|$ shows the maxima at frequencies similar to those in Fig. $2 \mathrm{~b}$ (not shown). Hence we can say in a crude sense that among the vertical propagating waves of $h \sim 200 \mathrm{~m}$, waves of $\tilde{\omega}=1 \sim 10$ tend to have large time-integrated (or time-averaged) energy if we can neglect the difference in the horizontal projection.

Figure 4 shows $\tilde{\omega}^{1 / 2}|\mathcal{U}|$ at $\zeta=0.1,2$ and 4.5 as functions of $h$ and $\tilde{\omega}$. At $\zeta=2$ (b), it has a maximum with respect to $\tilde{\omega}$ where $\tilde{\omega} \sim O(1)$ for $h>100 \mathrm{~m}$, whereas it has no clear maximum with respect to $\tilde{\omega}$ for $h<100 \mathrm{~m}$. The dependence on $h$, on the other hand, is similar to the non-dissipative case shown in Fig. 1 over a wide range of $\tilde{\omega}$; that is, a wide response around $h \sim 200 \mathrm{~m}$ and a sharp response at $h \sim 10 \mathrm{~km}$ are dominant. If the altitude $\zeta$ is higher, the response for $h<100 \mathrm{~m}$ decreases and the maximum shifts to larger $\tilde{\omega}$, while the response of low frequency $(\tilde{\omega}<1)$ is enhanced near the lower boundary.

The equivalent depth $h$ is not independent of frequency but is related to it as an eigenvalue of Laplace's tidal equations for each Hough mode. We show this relation in Fig. 5 for the convenience of comparison with Fig. 4, although original diagrams are shown by Longuet-Higgins (1968) for $s \leq 5$. Scales of $\tilde{\omega}$ for $\alpha^{-1}=7$ days and 21 days are shown on the right-hand side of the figure. When $\alpha^{-1}=O(10)$ days, $\tilde{\omega}$ s of inertio-gravity 
(a)
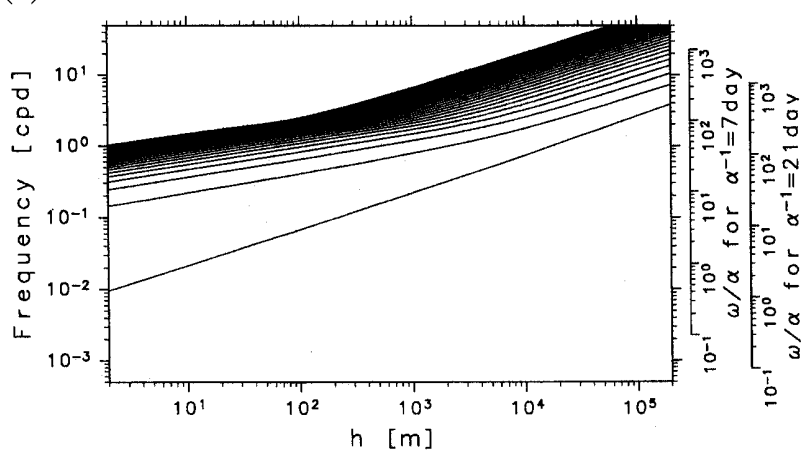

(b)

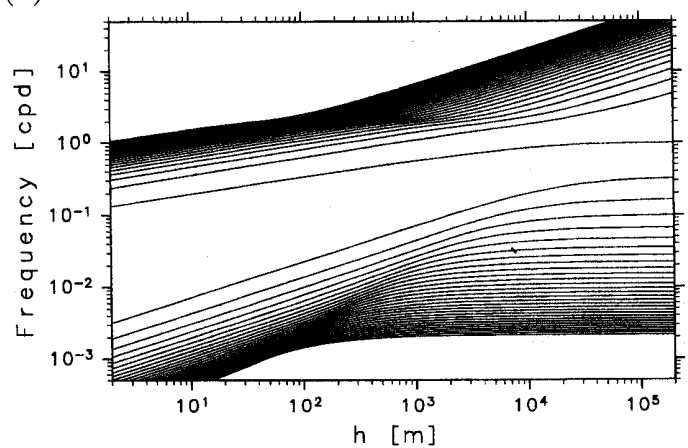

(c)

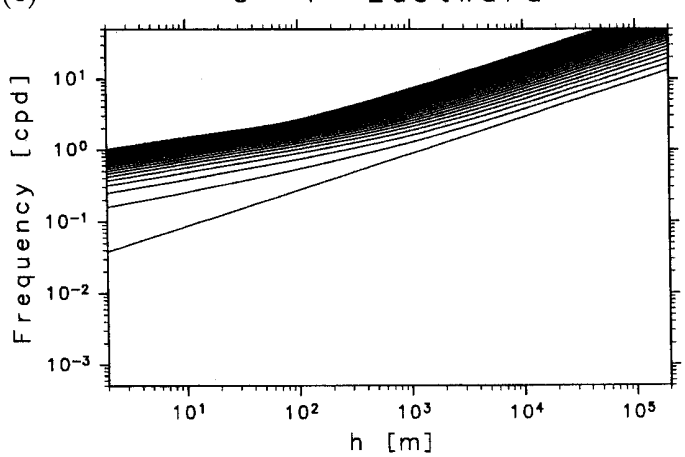

(d)

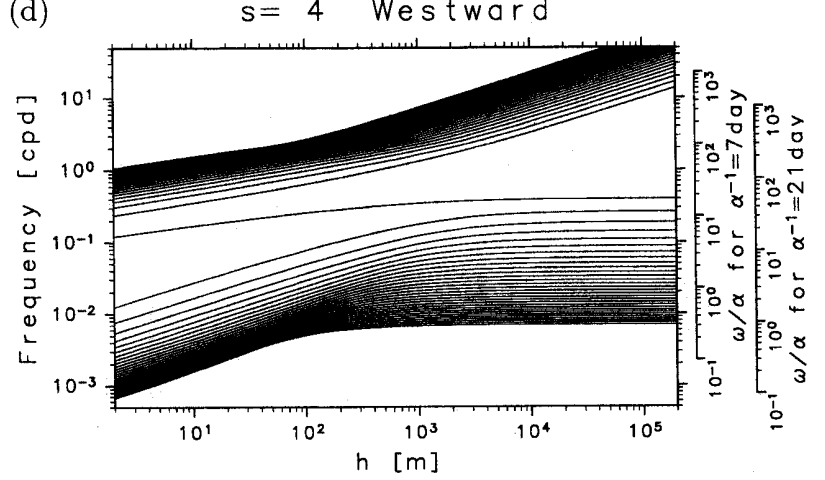

(e)
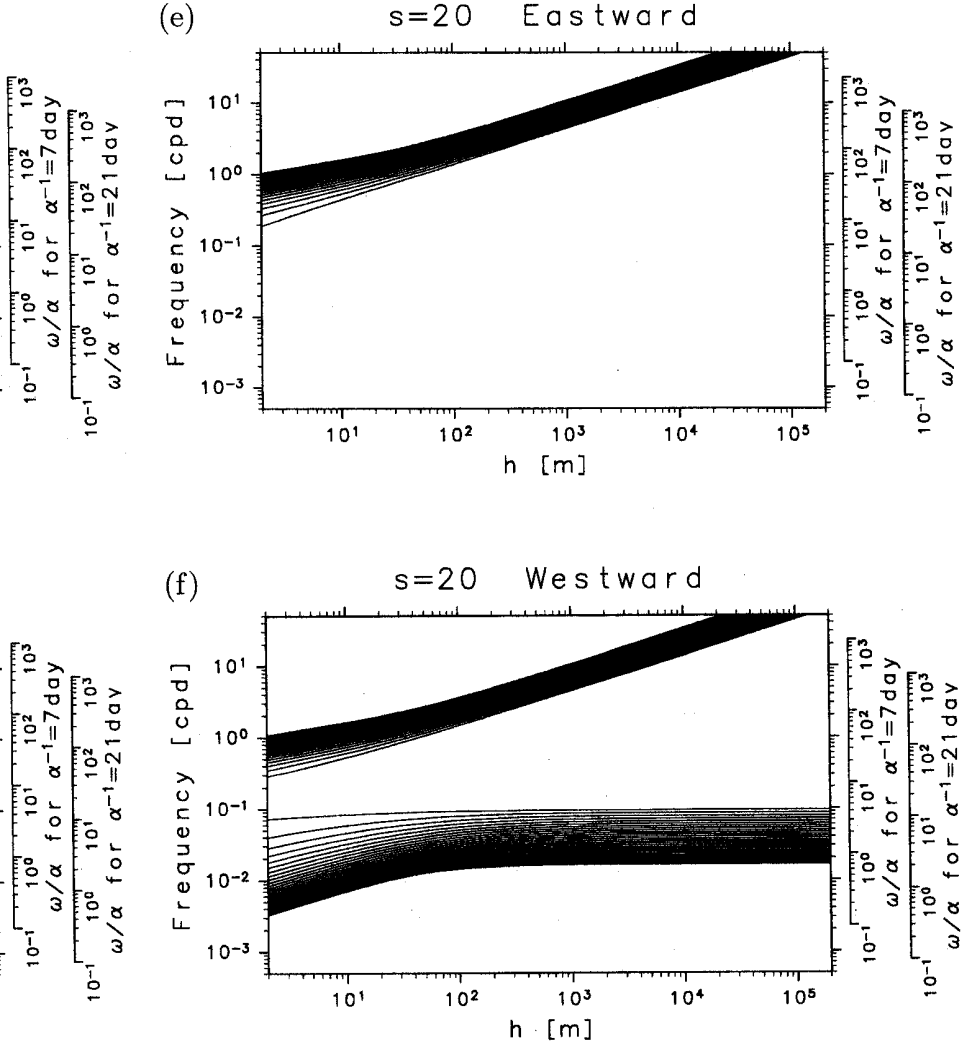

(f)

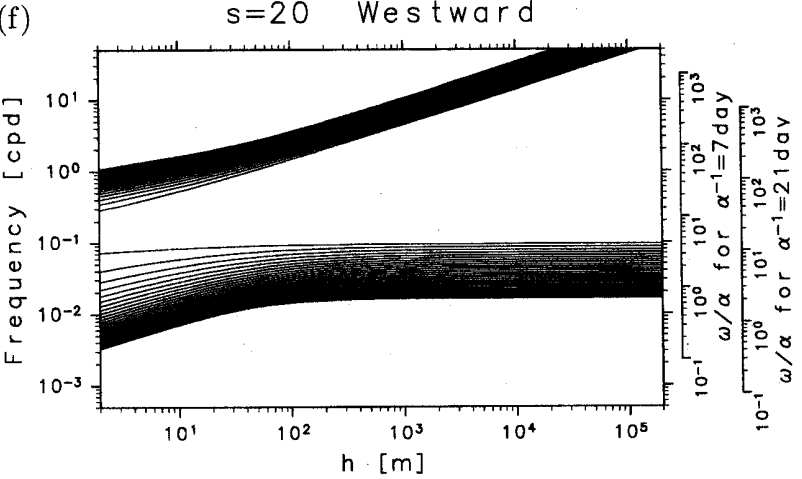

Fig. 5. Relationship between equivalent depth $(>0)$ and frequency of Hough functions of (a,b) $s=1$, $(\mathrm{c}, \mathrm{d}) s=4$, and $(\mathrm{e}, \mathrm{f}) s=20$. Scales on the right-hand side are $\tilde{\omega}$ for $\alpha^{-1}=7$ day and 21 days. Note that $h$ is shown over the same range as Fig. 4 .

waves for $h \sim 200 \mathrm{~m}$ are larger than $O(10)$ in (a)(f), those of Kelvin waves are comparable or larger than $O(10)$, and those of Rossby waves are $O\left(10^{-1}\right)$ $O\left(10^{1}\right)$. Since $\tilde{\omega}$ of gravity waves (inertio-gravity and Kelvin waves) are larger than $1 \sim 10$, where $\tilde{\omega}^{1 / 2}|\mathcal{U}|$ is large, they tend to have smaller amplitude than Rossby. waves. This tendency becomes larger for larger wavenumbers, since gravity waves have larger frequency for larger horizontal wavenumbers. That is, the response of gravity waves tends to be small compared with that of Rossby waves at large wavenumbers.

On the other hand, there is another mechanism which affects the ratio of Rossby waves and gravity waves, depending on the wavenumbers. Figures 3 and 5 show that if $h_{s n}^{\omega} \gg h_{0}, \frac{d \ln |\omega|}{d \ln \left|h_{s n}^{\omega}\right|} \rightarrow 0$ for Rossby waves. This implies that Rossby waves, which are non-divergent in this limit, are not excited for the following reason. Suppose that the solution of the vertical structure equation has large amplitude for $h$ such that $h_{a}<h<h_{b}$. The amplitude of the response of a Hough mode, nevertheless, is small if $\omega\left(h_{a}\right)$ of the mode is almost equal to $\omega\left(h_{b}\right)$, because Eq. (7) contains integration with $\omega$. Therefore, since $h_{0}$ decreases as the horizontal wavenumber increases; Rossby waves of sufficiently 

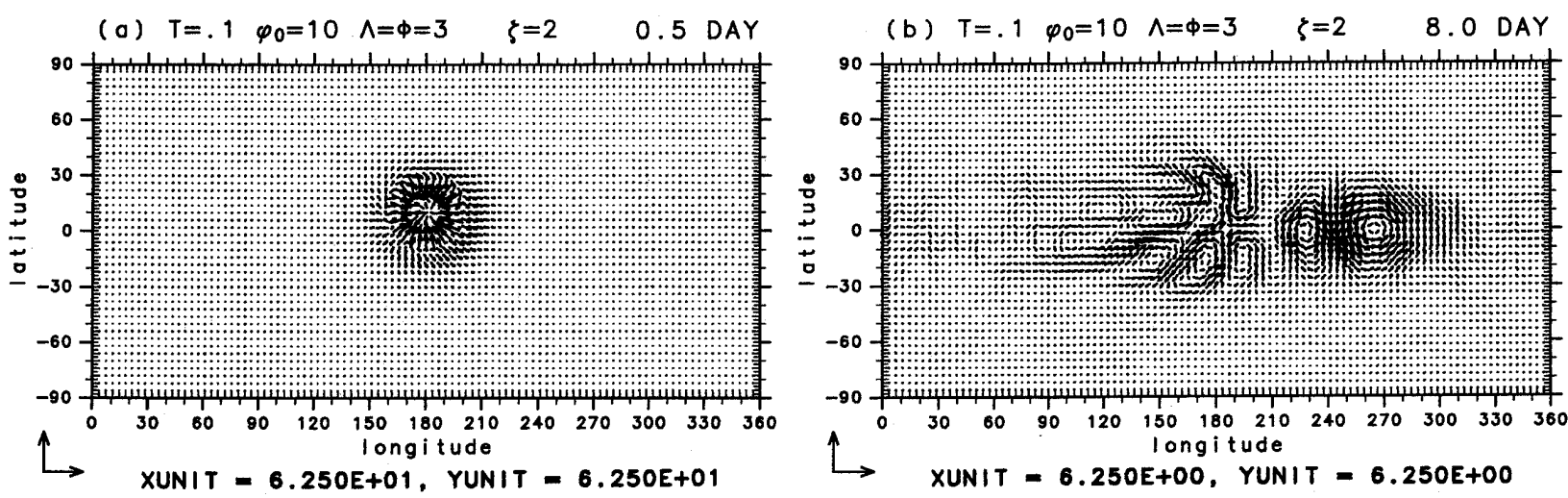

Fig. 6. Time evolution of horizontal wind field in Experiment (A) at $\zeta=2$ : (a) $t=0.5$ days and (b) $t=8$ days. The center of the heating is at $\lambda_{0}=180^{\circ}$ and $\varphi_{0}=10^{\circ}$. Unit vectors and their scale $\left[\mathrm{ms}^{-1}\right]$ are shown at the left-bottom corner and at the bottom, respectively.

large wavenumbers $\left(\gg 1 / l_{e}\right)$ are not readily excited. This is similar to the familiar geostrophic adjustment problem (or, the initial value problem) for initial surface displacement in a shallow water system; that is, as the horizontal scale of the displacement decreases, the amplitude of Rossby waves or geostrophic flow decreases. This is the case even if the initial displacement is near the equator.

The two mechanisms mentioned in the previous two paragraphs do not behave similarly. It is difficult to predict how these two work without actual calculations.

\section{The response to heating with Gaussian form}

\section{a. Numerical procedure}

Responses to localized heating are studied numerically with the method of separation of variables stated in Section 2 for twelve cases of different heating profiles. The vertical structure of the heating and that of thermal structure of the resting basic state are the same as in the previous sections, Eqs. (16) and (14), respectively. The Newtonian cooling rate $\alpha$ is set equal to $1 / 7 \mathrm{day}^{-1}$ from now on if it is not explicitly mentioned; there also are additional experiments with $\alpha=1 / 21$ day $^{-1}$.

The heating is assumed to have the following form as in SG and GS:

$J=e^{\zeta / 2} \mathcal{J}(\zeta) \exp \left[-\frac{\left(\lambda-\lambda_{0}\right)^{2}}{2 \Lambda^{2}}-\frac{\left(\varphi-\varphi_{0}\right)^{2}}{2 \Phi^{2}}-\frac{\left(t-t_{0}\right)^{2}}{2 T^{2}}\right]$,

where $\lambda_{0}, \varphi_{0}, t_{0}, \Lambda, \Phi$ and $T$ are constants, and note that $T$ in this paper corresponds to $T /(2 \pi)$ in SG. Since the heating is Gaussian with time and longitude, the time or zonal spectrum is also Gaussian. The spectrum of the response to this heating is, therefore, also applicable to the response to a stochastic random heating process with the same
Gaussian power spectrum (SG). Since $\lambda_{0}$ and $t_{0}$ have no effect on the spectrum, $\lambda_{0}$ and $t_{0}$ are fixed to $\pi$ and 0 , respectively. However, the present geometry has not such symmetry with respect to latitude, and $\varphi_{0}$ remains as an experimental parameter.

Table 1 shows the values of experimental parameters $\varphi_{0}, \Lambda, \Phi, T$ and $J_{0}$ for the twelve cases. The center of the heating is placed at $\varphi_{0}=10^{\circ}$ in the six experiments of $(\mathrm{A})-(\mathrm{F})$, while it is on the equator in $(\mathrm{G})-(\mathrm{L})$. The horizontal scale of the heating in (A), $(\mathrm{C}),(\mathrm{E}),(\mathrm{G}),(\mathrm{I})$ and $(\mathrm{K})$ is about $1,000 \mathrm{~km}$, which is comparable to or more than the typical scale of a tropical cloud cluster, while that in the remainder is about $3,000 \mathrm{~km}$, comparable to the typical scale of a super cloud cluster. The time scale of the life cycle of heating is about $1 / 3$ day in (A), (B), (G) and $(\mathrm{H})$, which is comparable to or less than that of a typical cloud cluster; it is about 1.5 days in (C), (D), (I) and $(\mathrm{J})$; and about 4.5 days in $(\mathrm{E}),(\mathrm{F})$, $(\mathrm{K})$ and $(\mathrm{L}) . J_{0} \Lambda \Phi T$ is set to be a constant so that the total heating integrated over space and time is approximately constant.

The total heating corresponds to the latent heat release due to precipitation of $1.6 \times 10^{14} \mathrm{~kg}$, which is about $1 / 3$ of the annual average of the observed precipitation per day between $15^{\circ} \mathrm{N}$ and $15^{\circ} \mathrm{S}$. Since the total heating is fixed, $J_{0}$ takes various values in Table 1. As a reference, a typical value of the heating observed in a cloud cluster is about $20 \mathrm{~K} /$ day (e.g., Johnson, 1992).

The linear calculation is done numerically for zonal wavenumbers of $|s| \leq 50$ and 240 discrete frequencies of 0.0034 day $^{-1} \leq \omega / 2 \pi \leq 4$ day $^{-1}$. The number of Hough functions for each wavenumber and frequency is 150 at maximum: 60 gravity waves (a half of them are eastward propagating and others are westward propagating), 60 waves with negative $h$ (both eastward and westward propagating), and 30 Rossby waves. Here, both Kelvin and Rossbygravity waves are counted as gravity waves for con- 

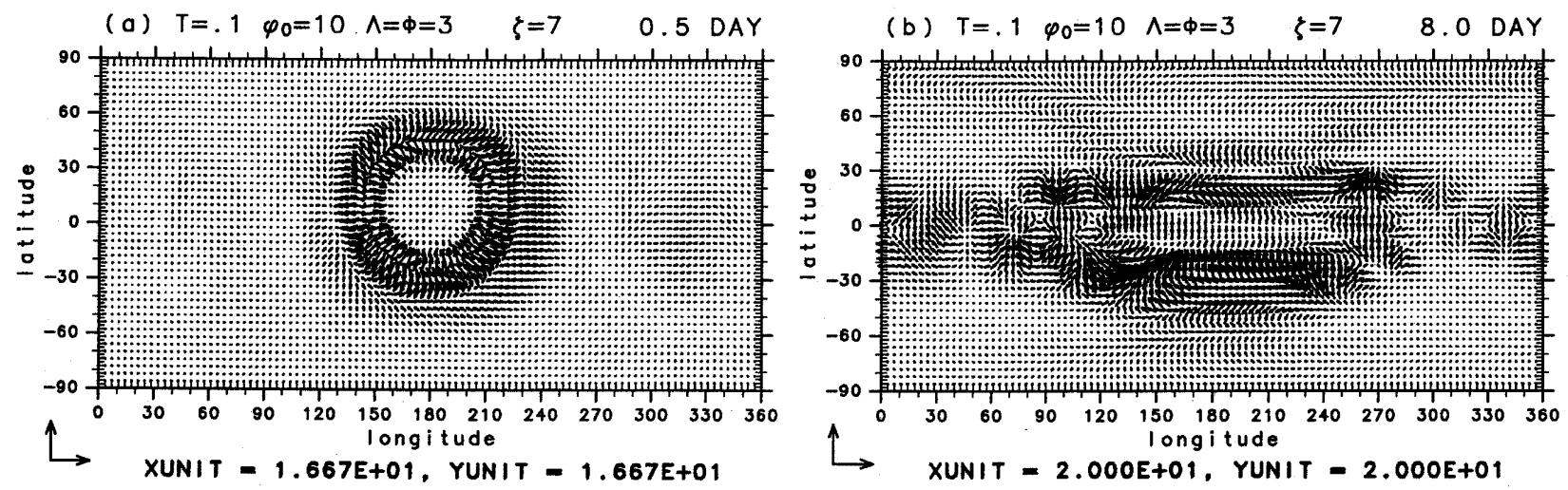

Fig. 7. As in Fig. 6, but for $\zeta=7$.
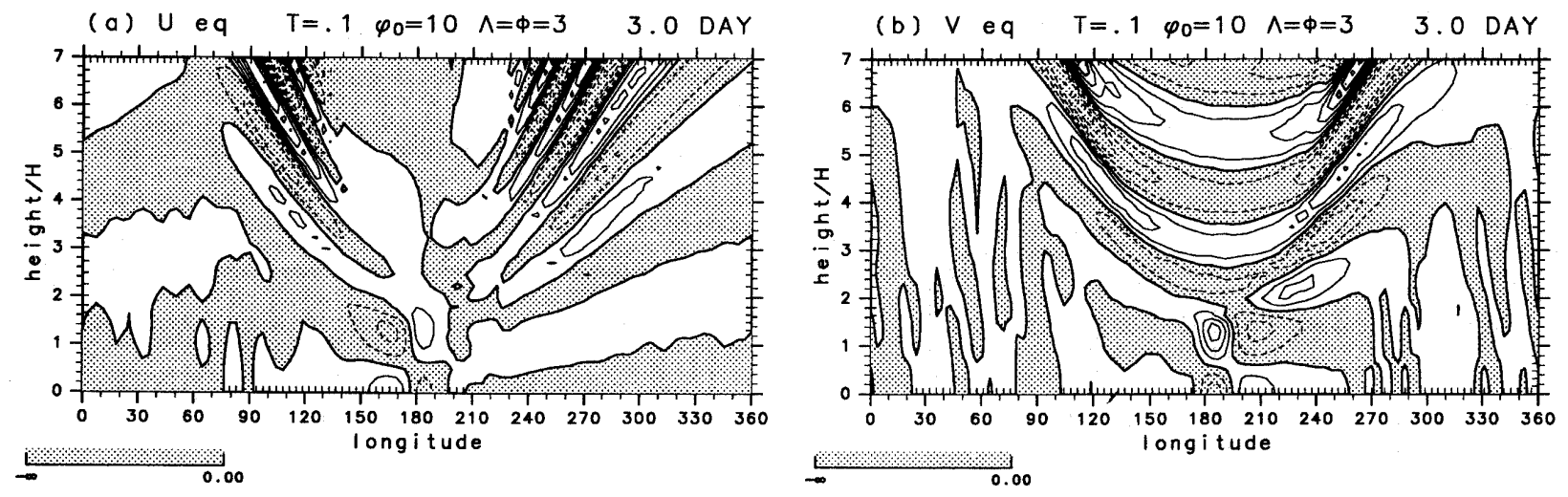

Fig. 8. Equatorial cross sections of (a) zonal wind field and (b) meridional wind field in Experiment (A) at $t=3$ days. The contour interval is $4 \mathrm{~ms}^{-1}$ and negative values are shaded.

venience, although westward Rossby-gravity waves are more like Rossby waves.

\section{b. Time evolution of the responses in flow field}

Firstly we describe the responses in physical space to show a typical time evolution of the flow field in the experiment (A). Figure 6 shows the time evolution of the horizontal wind field at $\zeta=2$ slightly above the tropopause. At first, inertio-gravity waves spread concentrically; Fig. 6a shows such a pattern at $t=0.5$ days (the heating has its maximum at $t=0$ ). Then the pattern is deformed and spreads zonally in low-latitudes after $t=1.5$ days. Vortical motion is seen both in the east and the west of the heating region at $t=8$ days (b). A packet of Rossby-gravity waves is located from $210^{\circ}$ to $300^{\circ}$ in longitude, while a packet of Rossby waves is seen from $90^{\circ}$ to $200^{\circ}$; they are identified in the superpositions only of Rossby-gravity waves and Rossby waves, respectively. Note that zonal group velocity of Rossby-gravity waves is always eastward while that for Rossby waves of larger horizontal scales than the deformation radius is westward.

Figure 7 also shows the horizontal wind field at $\zeta=7$ (about $50 \mathrm{~km}$ ). In the initial phase (a), concentric inertio-gravity waves spread more wider than those at $\zeta=2$. The pattern is also deformed and begins to spread zonally in low latitudes after $t=1.5$ days. At $t=8$ days (b), horizontal wind response is largely confined to low latitudes; not only vortical motion but also divergent motion is seen at this height. Note, also, weak large-scale vortical motions in middle and high latitudes.

The horizontal wind field is almost symmetric about the center of the heating in the initial phase, and asymmetry becomes discernible afterwards. Figure 8 shows vertical cross sections of horizontal wind field, $u(\mathrm{a})$ and $v(\mathrm{~b})$, on the equator at $t=3$ days. In the middle atmosphere, the zonal wind perturbation (a) gradually becomes more active in the east of the heating region because of the existence of Kelvin waves which have eastward group velocities. In the troposphere, on the other hand, Rossby wave motion dominates in the west of the heating region. As for the meridional wind (b), a packet of Rossby-gravity waves is conspicuous in the east of the heating region.

Experiment (D) gives another type of response for a larger scale heating with a longer life cycle. Figure 9 shows the horizontal wind field at $\zeta=2$. In the initial phase (a), a pair of vortices are formed in the 

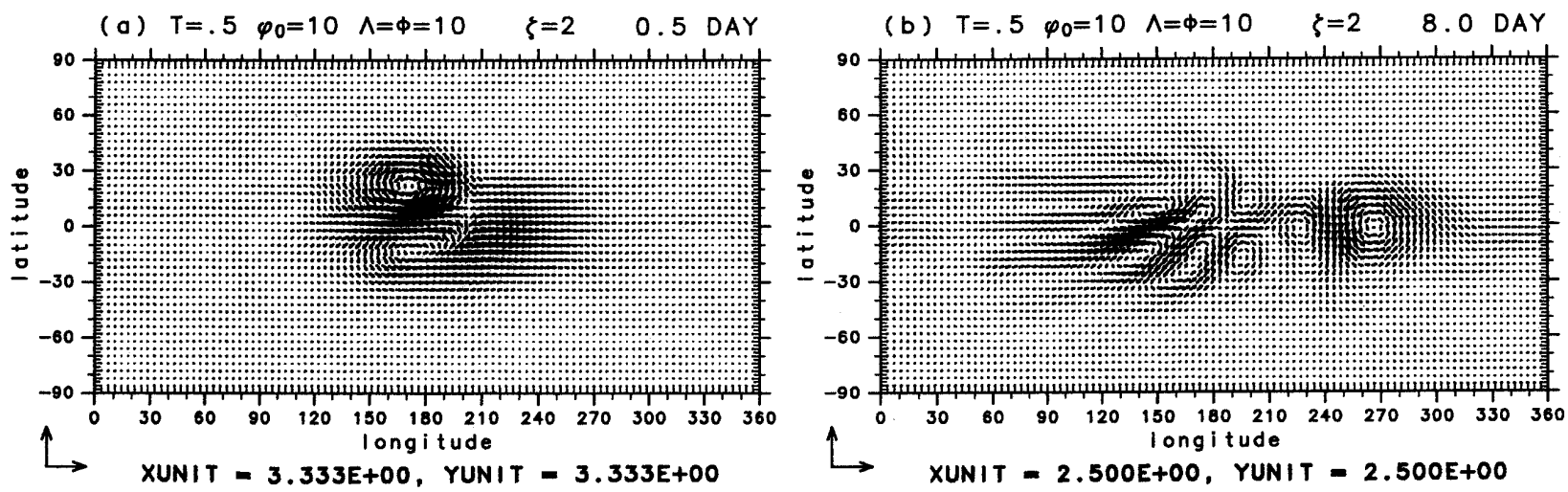

Fig. 9. As in Fig. 6, but for Experiment (D).
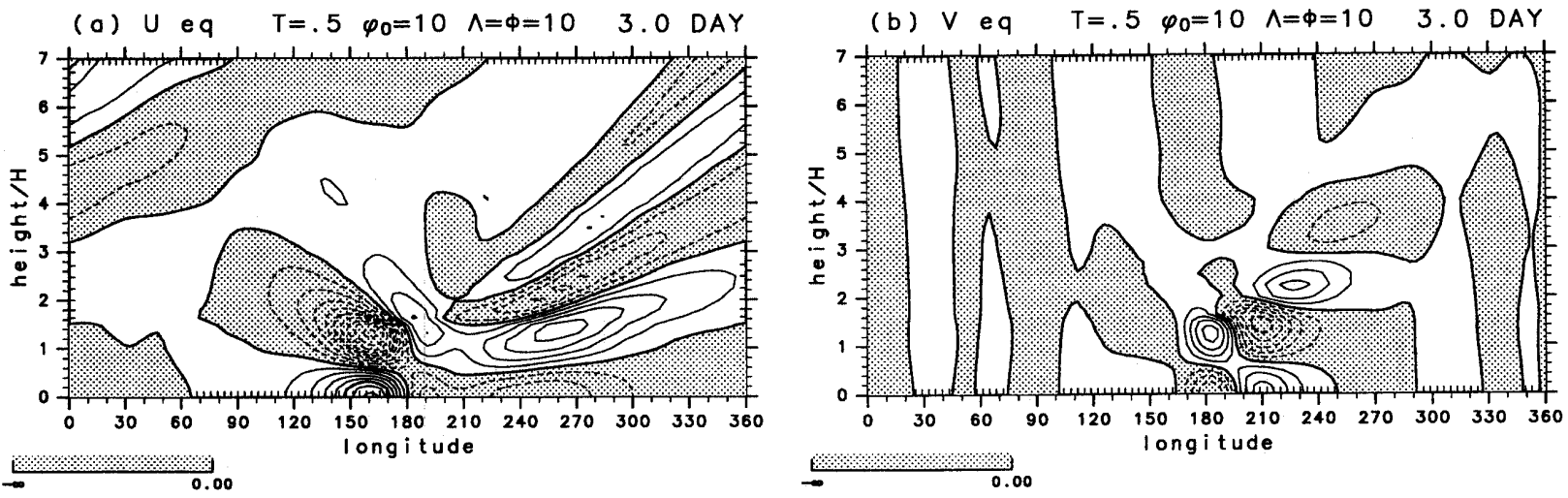

Fig. 10. As in Fig. 8, but for Experiment (D). The contour interval is $0.5 \mathrm{~ms}^{-1}$.

west of the heating region, and a region of eastward wind is formed in the east. These constitute the so called "Gill pattern" which was firstly obtained as a steady response to continuous heating (Gill, 1980). The vortices are identified to be Rossby waves and the eastward wind region to be Kelvin waves. This perturbation spreads zonally in low latitudes with time, and at $t=8$ days (b), vortical motions similar to those obtained in (A) [Fig. 6b] are seen in low latitudes with a larger size of vortical pattern. The wind field at $\zeta=7$ shows the dominance of Kelvin waves in zonal motion after $t=1.5$ days and that of vortical motions afterwards (not shown).

Figure 10 shows vertical cross sections of horizontal wind on the equator at $t=3$ days. The zonal wind field (a) mainly consists of Kelvin and Rossby waves, while the meridional wind field (b) mainly consists of Rossby-gravity waves.

Global normal modes are dominant in middle and high latitudes. Figure 11 is a time-longitude section of geopotential height perturbation at $\varphi=60^{\circ}$ and $\zeta=7$. A westward-propagating 5 -day wave of zonal wavenumber 1 is clearly seen with an amplitude of $2 \sim 3 \mathrm{~m}$. A similar diagram for the experiment (A) also shows a 5-day wave signal with similar amplitude, although it is not very clear because of the superposition of other types of perturbations.

Horizontal cross sections of all experiments with $T=0.1$ days (A, B, G and $\mathrm{H}$ ) show concentric patterns in the initial phase, which then spread zonally in low latitudes as shown in Figs. 6 and 7. On the other hand, those of all experiments with $T=0.5$ days and $T=1.5$ days $(\mathrm{C}-\mathrm{F}$ and $\mathrm{I}-\mathrm{L})$ show the Gill pattern in the initial phase and then they spread zonally in low-latitudes, as shown in Fig. 9. The difference in horizontal scale of the heating affects only the horizontal size of each response pattern.

\section{c. Energy distribution to various kinds of wave}

Time evolutions of flow field in the previous subsection were calculated by the superposition of all of the Hough modes we retained. In the subsection, we used the terminology of waves rather vaguely; for example, "The vortices are identified to be Rossby waves and the eastward wind region to be Kelvin waves". However, one of the greatest advantage of the present method of separation of variables is that we can discuss the behavior of each wave separately. The separation can be done uniquely by use of the Hough modes. In this subsection, the energy distribution in each mode is examined by classifying the modes into five kinds of wave: Kelvin waves, inertiogravity waves, Rossby-gravity waves, Rossby waves, 


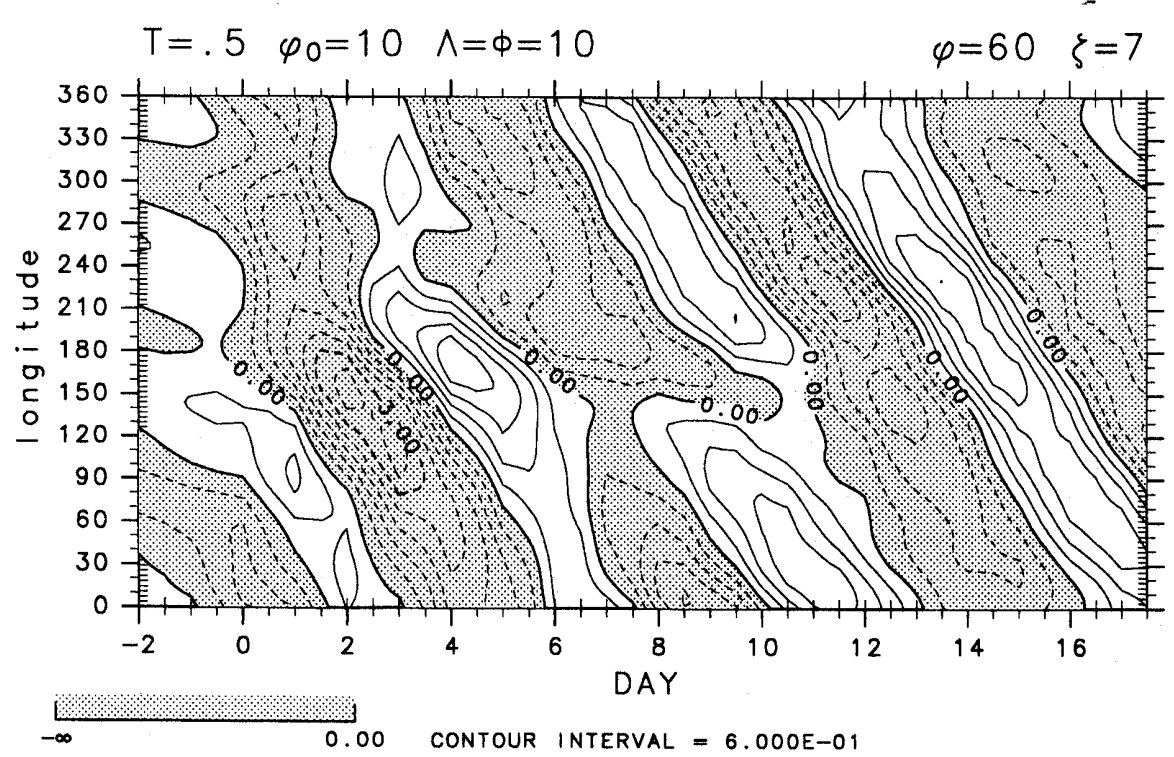

Fig. 11. Time-longitude section of geopotential height deviation $[\mathrm{m}]$ in Experiment (D) at $\varphi=60^{\circ}$ and $\zeta=7$. The contour interval is $0.6 \mathrm{~m}$ and negative values are shaded.
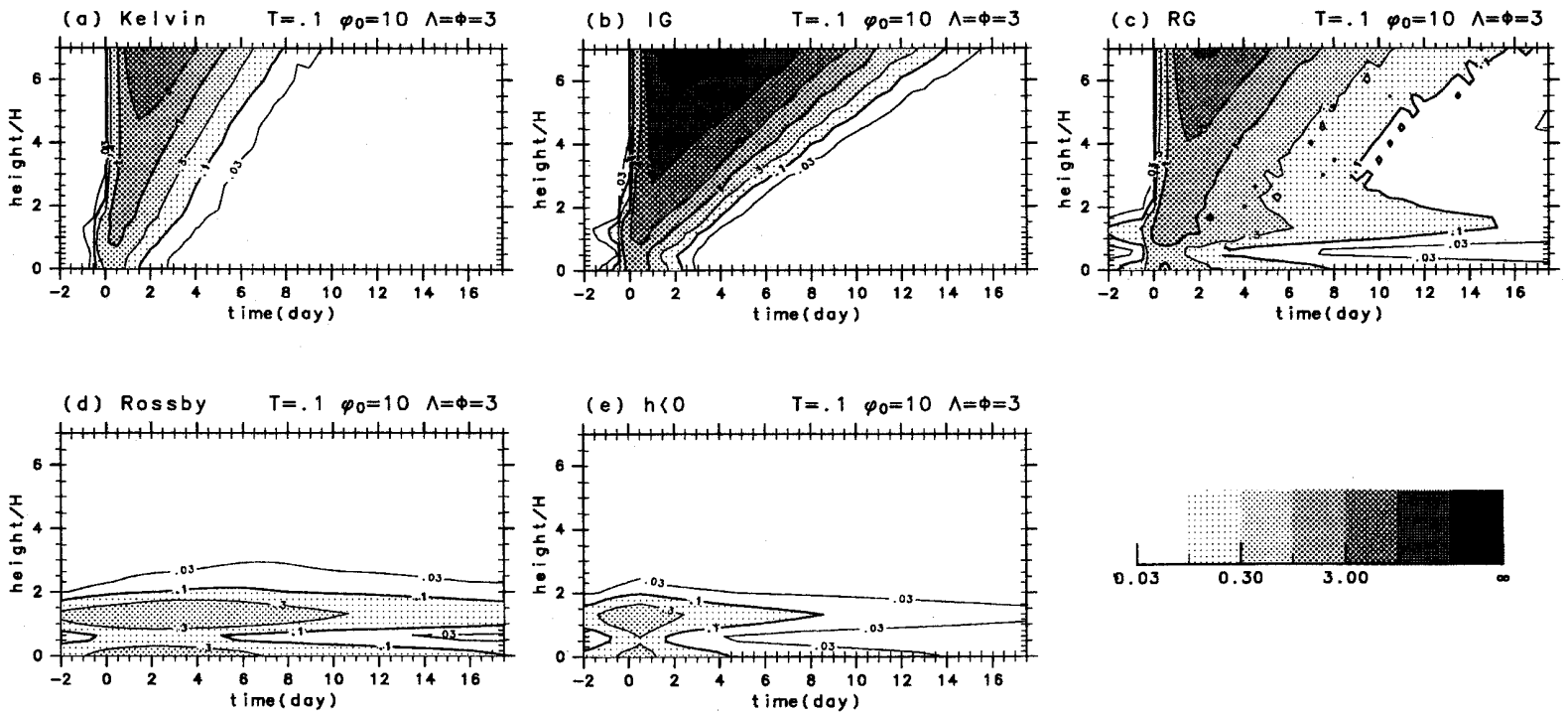

Fig. 12. Time evolution of horizontally averaged wave energy $E_{i}(\zeta, t)\left[\mathrm{m}^{2} \mathrm{~s}^{-2}\right]$ of each kind of wave in Experiment (A): (a) Kelvin waves, (b) inertio-gravity waves, (c) Rossby-gravity waves, (d) Rossby waves, and (e) waves of $h<0$.

and waves of $h<0$.

Figure 12 shows the time evolution of energy of each kind of wave in the experiment (A). Horizontally averaged energy of the $i$-th kind of wave, $E_{i}(\zeta, t)$, is defined as follows:

$$
\begin{aligned}
& E_{i}(\zeta, t) \equiv \frac{1}{4 \pi} \int_{0}^{2 \pi} \int_{-\pi / 2}^{\pi / 2} \frac{1}{2} \\
& \left(u_{i}^{2}+v_{i}^{2}+\frac{1}{N^{2} H^{2}}\left(\frac{\partial \Phi_{i}^{\prime}}{\partial \zeta}\right)^{2}\right) \cos \varphi d \varphi d \lambda,
\end{aligned}
$$

where $u_{i}, v_{i}$, and $\Phi_{i}^{\prime}$ consist only of the components of that kind. Such separation of the total energy into
$E_{i}$ is not complete in principle for time evolution because there is no orthogonality between Hough functions of different frequencies. This is the reason why $E_{i}$ s look like having significant energy before significant heating exists. Particularly those of Rossby waves and waves of $h<0$ have such a tendency because of their low frequencies. Nevertheless, $E_{i}(\zeta, t)$ is useful to examine the gross features of the timedependent activity of each kind of wave, particularly for the time evolution after the heating is applied.

Kelvin waves (a) and inertio-gravity waves (b) propagate upward more rapidly than other waves, while Rossby waves (d) and waves of $h<0$ (e) stay 


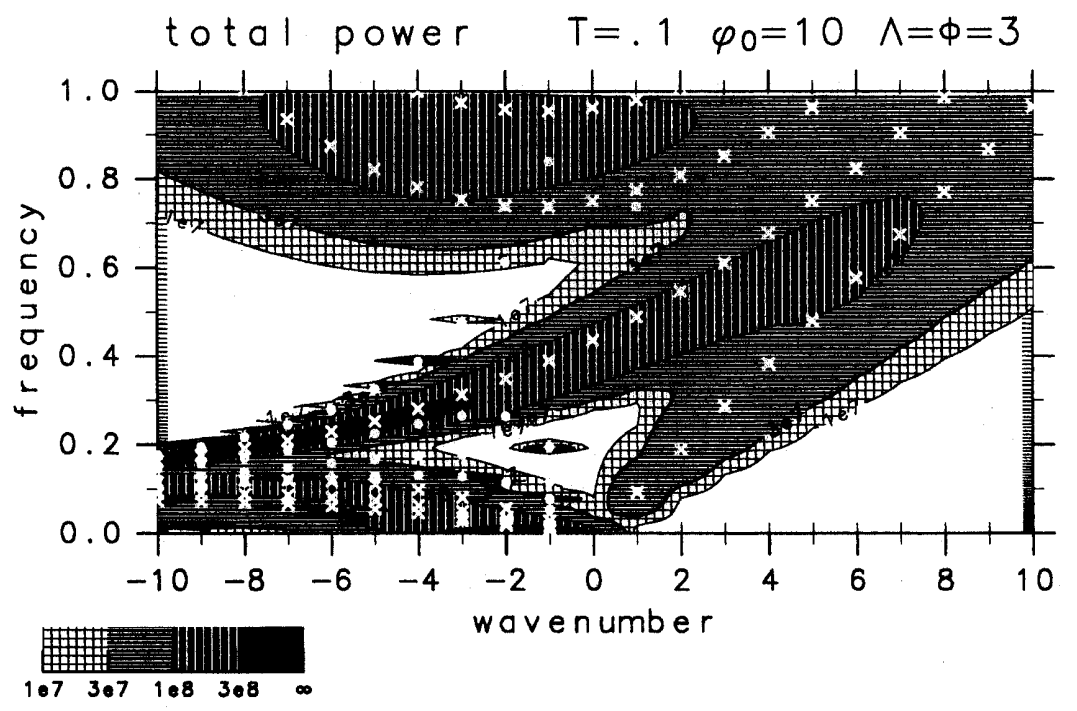

Fig. 13. Zonal wavenumber-frequency spectrum $2 E_{s}^{\omega}(\zeta)$ at $\zeta=2$ in Experiment (A). The unit of the ordinate is cycle per day. Symbols $\bullet$ and $x$ denote the dispersion relation of Hough functions for $h=10 \mathrm{~km}$ and $h=200 \mathrm{~m}$, respectively. The former corresponds to global normal modes and the latter vertically propagating waves with vertical wavelength about $13 \mathrm{~km}$; only some gravest modes are shown for each wavenumber.

near the forcing region because they have small vertical group velocities. Rossby-gravity waves (c) have two components; one propagates upward rapidly and the other stays near the forcing region. The former consists of eastward-propagating waves which are more like gravity waves while the latter consists of westward-propagating waves which are more like Rossby waves. In this experiment inertio-gravity waves are more vigorous than Kelvin waves and stay longer in the middle atmosphere. The response of Rossby waves remains much longer just above the forcing region. Waves of $h<0$ are vertically evanescent and stay in the troposphere.

Figure 13 is the zonal wavenumber-frequency spectrum of the total energy, $2 E_{s}^{\omega}(\zeta)$, at $\zeta=2$ in the experiment (A). It is defined so as to be proportional to the time-integrated energy for each frequency and zonal wavenumber:

$E_{s}^{\omega}(\zeta) \equiv \frac{1}{2} e^{\zeta} \sum_{n}\left[\frac{k_{s n}^{\omega}}{g h_{s n}^{\omega}}\left|\mathcal{U}_{s n}^{\omega}(\zeta)\right|^{2}+\frac{1}{N^{2} H^{2}}\left|\mathcal{T}_{s n}^{\omega}(\zeta)\right|^{2}\right]$

where $k_{s n}^{\omega}$ is the ratio of kinetic energy and potential energy in the separated shallow water system (Laplace's tidal equations). Note that $k_{s n}^{\omega}$ is about 1 for gravity waves of sufficiently large $h$ and Rossby waves of sufficiently small $h$ (see Figs.13 and 14 in Longuet-Higgins, 1968), and that if there is no dissipation and if $\frac{N H}{\sqrt{g h_{s n}^{\omega}}}$ is sufficiently larger than $\frac{1}{2}$, $\frac{1}{g h_{s n}^{\omega}}\left|\mathcal{U}_{s n}^{\omega}\right|^{2} \sim \frac{1}{N^{2} H^{2}}\left|\mathcal{T}_{s n}^{\omega}\right|^{2}$ from Eqs. (9), (10), and (12). Figure 13 can be interpreted as the weight for the projection from heating to response in the spectral space. This weight is common to any heat- ing with the same vertical and meridional structure, since the spectrum of the heating (A) is almost white within the range shown in Fig. 13. Here note that the spectrum of the heating is proportional to $\exp \left(-s^{2} \Lambda^{2} / 2-\omega^{2} T^{2} / 2\right)$, and that $s=19$ and $\omega / 2 \pi=1.6$ day $^{-1}$ give $s \Lambda=1$ and $\omega T=1$, respectively for the values of $\Lambda$ and $T$ in the experiment (A).

As discussed in Section 3, the dominant responses are equatorially-trapped vertically-propagating waves whose vertical scale matches that of the heating as well as global normal modes. Broad responses are seen near the points denoted by the symbol $\times$ which shows the dispersion relation of Hough modes of $h=200 \mathrm{~m}$, while sharp responses are seen around the points denoted by $\bullet$ which shows that of $h=10 \mathrm{~km}$. The spectrum at lower or higher levels has similar features (not shown), but the low (high) frequency response is enhanced at lower (higher) levels. Low-frequency waves dissipate in low levels, since they have small $h$ and then have small vertical group velocities, as well as for the reason that the dissipation term is proportional to $\tilde{\omega}$ (Subsection 3a). Because of this frequency shift, the dominant vertical wavelength becomes longer with height in the middle atmosphere.

In the second paragraph from last in Subsection $3 c$, we pointed out a mechanism which affects the ratio of Rossby waves and gravity waves depending on the horizontal scales. It suppresses Rossby waves of zonal wavenumber $s$ sufficiently larger than $s_{r} \equiv 1 / l_{e}$. In the experiment (A), it suppresses global Rossby normal modes of $s$ larger than about 
(A) $T=.1 \quad \varphi_{0}=10 \quad \wedge=3 \quad \phi=3$

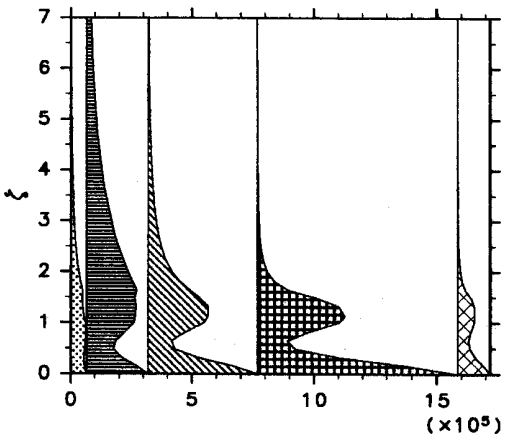

(B) $T=.1 \quad \varphi_{0}=10 \quad \Lambda=10 \quad \phi=10$

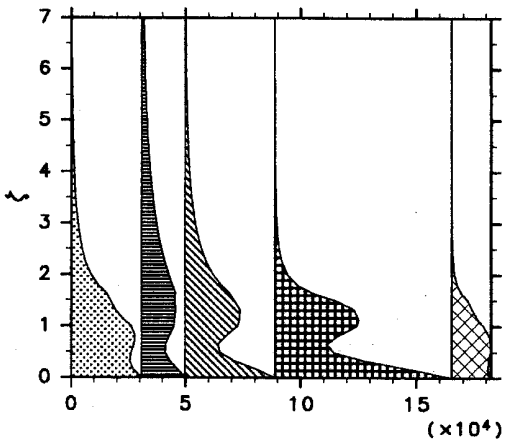

(C) $T=.5 \quad \varphi_{0}=10 \quad \Lambda=3 \quad \phi=3$

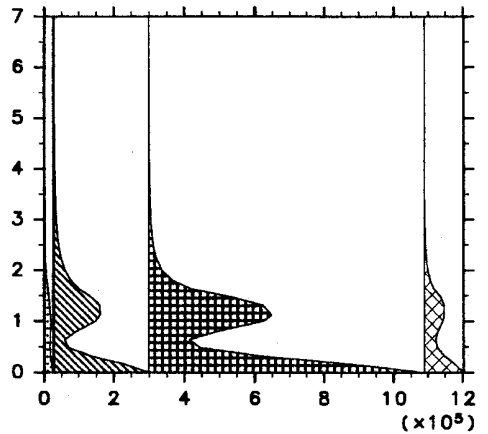

(D) $T=.5 \quad \varphi_{0}=10 \quad \wedge=10 \quad \phi=10$

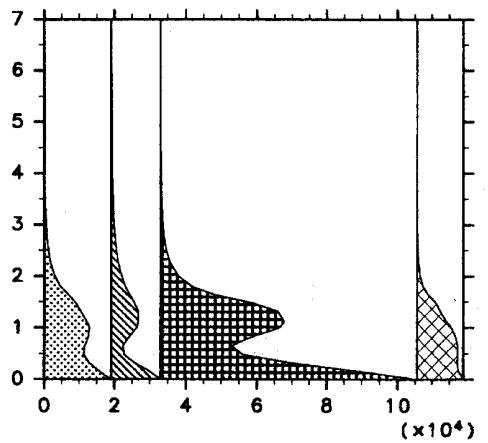

(E) $T=1.5 \quad \varphi_{0}=10 \quad \Lambda=3 \quad \phi=3$

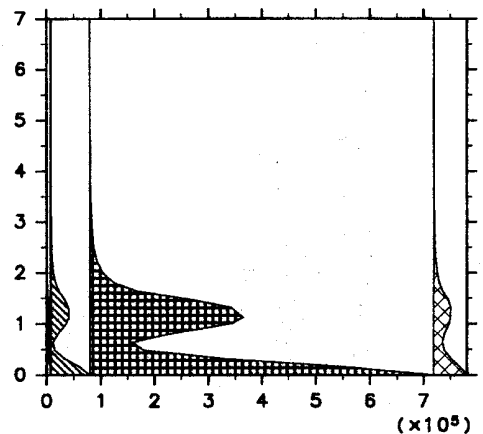

(F) $T=1.5 \quad \varphi_{0}=10 \quad \wedge=10 \quad \phi=10$

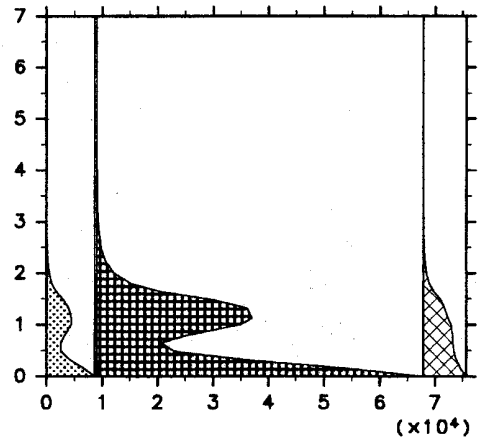

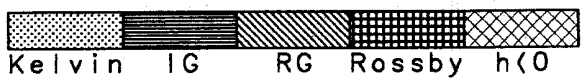

Fig. 14. Horizontally-averaged, time-integrated, and mass-weighted energy $e^{-\zeta} \overline{E_{i}}(\zeta)\left[\mathrm{m}^{2} \mathrm{~s}^{-1}\right]$ of each kind of wave in the experiments $(\mathrm{A})-(\mathrm{F})$.

10 , since $s_{r} \sim 1.6$ for $h=10 \mathrm{~km}$. However, it does not effectively suppress vertically-propagating Rossby waves within the present truncation at zonal wavenumber 50 , although $s_{r} \sim 4.2$ for $h=200 \mathrm{~m}$.

In order to show the dependence of the wave responses on heating parameters, this kind of spectral information is compressed further. Figure 14 shows the vertical energy distribution of five kinds of wave in the experiments $(\mathrm{A})-(\mathrm{F})$; the horizontally averaged energy spectrum as shown in Fig. 13 is weighted by the air mass and integrated over frequency and zonal wavenumber for each kind of wave to get $\int_{-\infty}^{\infty} e^{-\zeta} E_{i}(\zeta, t) d t$. In this case, the separation of the total energy into each kind of wave is complete for the time-integrated quantity. If the time scale of the heating is large $(T=1.5$ days $)$, the response consists mainly of Rossby waves. As the time scale of the heating decreases (i.e., frequency spectrum approaches a white one) with fixed horizontal scale, the ratio of Rossby-wave energy to the total energy decreases gradually, while inertio-gravity and Kelvin waves increase their ratio largely. The ratio of Rossby-gravity waves also increases, but waves of $h<0$ are not sensitive to the time scale $T$. Note also that the total energy of the response increases as $T$ decreases, as is expected from the fact that the total heating instead of the total squared heating is fixed. The increase of gravity-wave responses, such as Kelvin, inertio-gravity, and eastward-propagating Rossby-gravity waves with decreasing $T$, is simply explained by the fact that these waves have large projection in the relatively high-frequency region.

On the other hand, as the horizontal scale of the heating decreases (i.e., the horizontal spectrum approaches a white one) with fixed time scale, the ratio of Kelvin-wave energy to the total energy decreases, that of inertio-gravity-wave energy increases, and that of Rossby-wave energy slightly increases. The change of Kelvin and inertio-gravity waves is mainly due to the change of the meridional projection. In the experiments $(\mathrm{A})-(\mathrm{F})$, both of the longitudinal and meridional scales of the heating are changed. However, if only the longitudinal scale of the heating decreases, both of the ratios of Kelvin-wave energy and inertio-gravity-wave energy to the total energy decrease while that of Rossby-wave energy increases; this dependence on the longitudinal scale was confirmed by additional experiments by changing $\Lambda$ from $2^{\circ}$ to $30^{\circ}$ with the other parameters fixed at $\varphi_{0}=10^{\circ}, \Phi=10^{\circ}$, and $T=0.01$ days.

Decrease of the mass weighted energy in the middle atmosphere is due to the dissipation by the Newtonian cooling. The attenuation of Rossby waves with height is more conspicuous than other ver- 
(G) $T=.1 \quad \varphi_{0}=0 \quad \Lambda=3 \quad \phi=3$ (1) $T=.5 \quad \varphi_{0}=0 \quad \Lambda=3 \quad \phi=3$ (K) $T=1.5 \quad \varphi_{0}=0 \quad \wedge=3 \quad \phi=3$
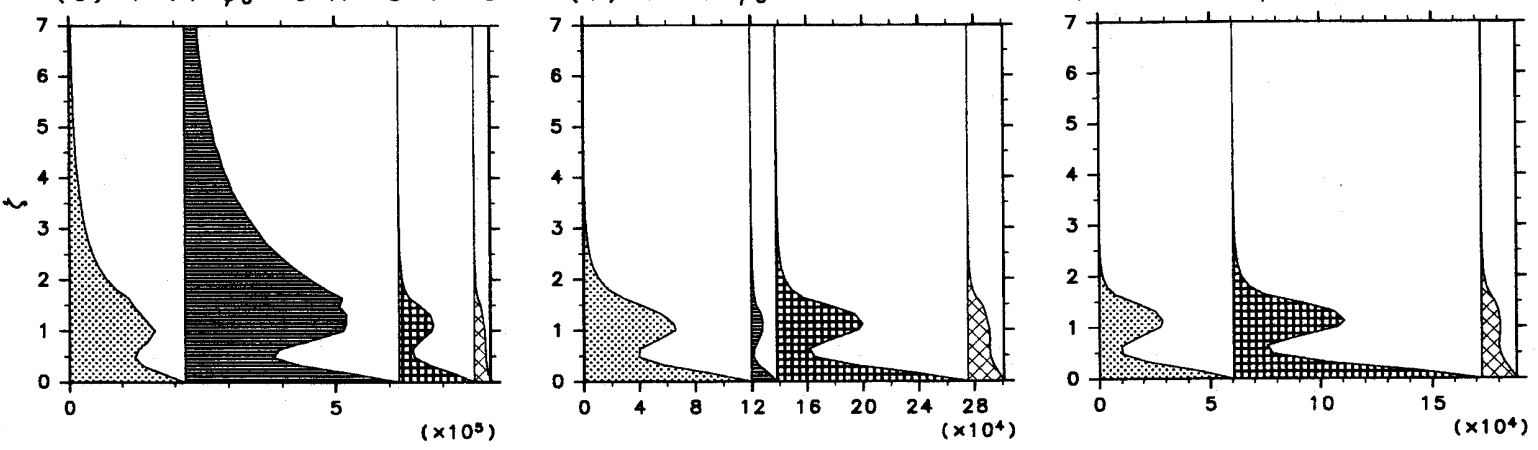

(H) $T=.1 \quad \varphi_{0}=0 \quad \Lambda=10 \quad \phi=10$
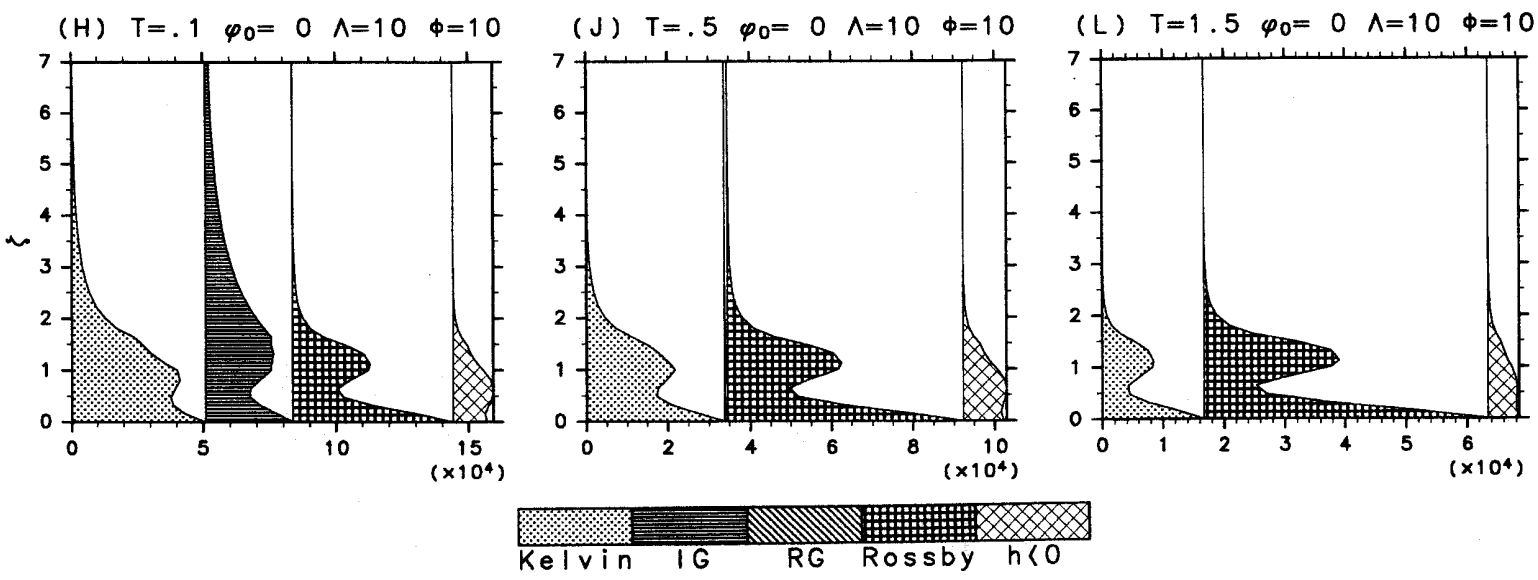

Fig. 15. As in Fig. 14 but for the experiments (G)-(L).

tically propagating waves, because Rossby waves propagate upward more slowly. The attenuation rates of Kelvin waves and inertio-gravity waves with height increase as the time scale of the heating $T$ increases since in general low frequency waves suffer large attenuation in the course of the vertical propagation.

Figure 15 is a similar diagram as Fig. 14 but for the experiments $(\mathrm{G})-(\mathrm{L})$; the center of the heating is just on the equator. There is, of course, no response of antisymmetric modes with respect to the equator such as Rossby-gravity waves. As the time scale of the heating $T$ decreases with fixed horizontal scale, the ratio of Rossby-wave energy to the total energy decreases as in Fig. 14. As the horizontal scale of the heating decreases with fixed time scale, on the other hand, Rossby-wave responses also decrease. Generally the heating just on the equator is less effective in exciting Rossby waves than that off the equator, while it is more effective to excite gravity waves. This dependence on the meridional position of the heating is explained by the meridional structure of the Hough functions near the equator; Hough functions of gravity waves which are symmetric about the equator have a local maximum on the equator, while those of symmetric Rossby waves have local minimum on the equator (see figures in Longuet-Higgins, 1968). Thus experiments with smaller meridional scales of the heating in Fig.
15 have less Rossby wave responses compared with gravity waves, since the heating is more confined near the equator.

As mentioned in Section 3, it is difficult to deduce the dependence of the response on horizontal scales of the heating without actual calculations. However, the present result shows a rather simple dependence on the zonal scale; às it decreases, Rossby-wave responses increase slightly relatively to gravity-wave responses. This tendency is qualitatively opposite to that of the geostrophic adjustment problem in a shallow water system, in which problem Rossbywave responses or geostrophic components decrease as the horizontal scale of the initial surface displacement decreases. On the other hand, the meridional scale and the meridional position of the heating alter the meridional projection of the heating onto Hough functions greatly. Thus the character of the solution of the vertical structure equation does not appear directly in the meridional scale dependence.

We also conducted an additional series of experiments with $\alpha^{-1}=21$ days; the results stated in this subsection are qualitatively unchanged.

\section{d. Zonal momentum flux}

Vertical flux of zonal momentum is expressed as the vertical component of Eliassen-Palm (EP) flux. Divergence of the EP flux is the only eddy-forcing term to change the zonal mean zonal momentum in 

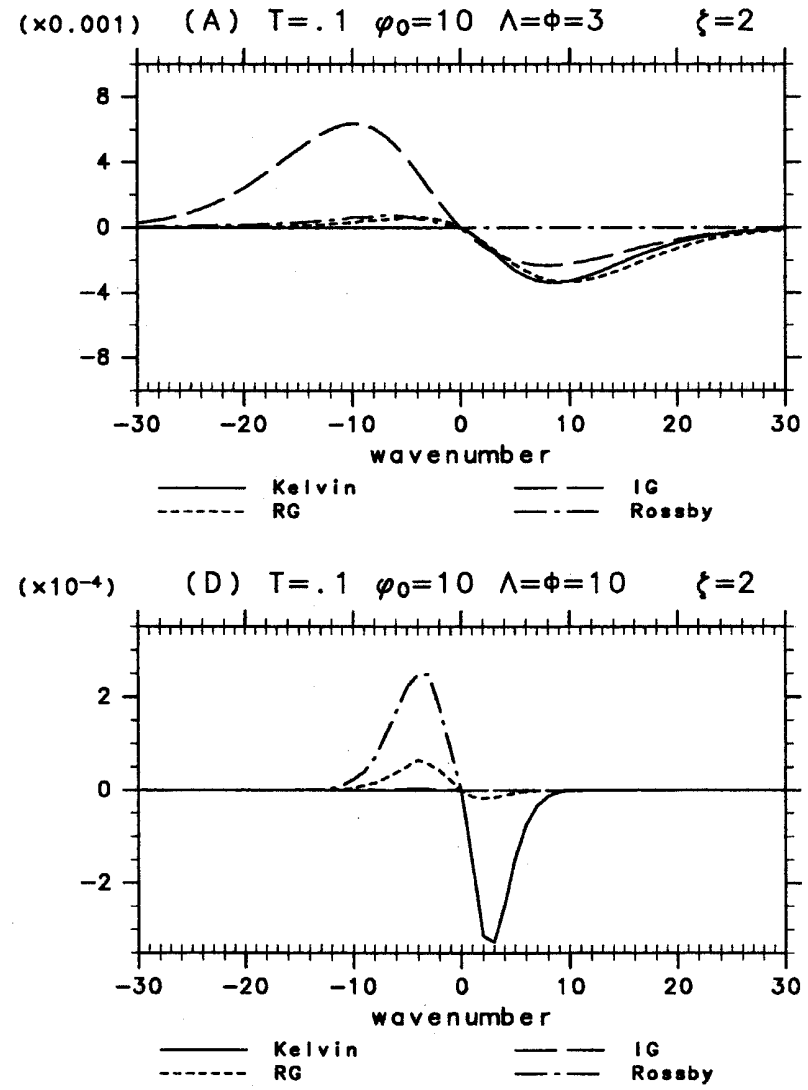

Fig. 16. Zonal momentum flux $\mathcal{F}_{i}\left[\mathrm{~ms}^{-1}\right]$ of each kind of wave at $\zeta=2$ for each zonal wavenumber; left: (A) and right: (D).

the transformed Eulerian-mean equations. For the present system of a resting basic state it is written as follows:

$$
F^{(z)}=\rho_{0} a \cos \varphi\left(f \overline{v \Phi_{z}^{\prime} / N^{2}}-\overline{w u}\right),
$$

in the standard notation (see Andrews et al., 1987), where the over-bar denotes the zonal mean. Generally this quantity cannot be separated into components of Hough modes because of the lack of orthogonality in the meridional structure between $v$ and $\Phi_{z}^{\prime}$ or between $w$ and $u$. In the region without heating nor dissipation, however, it can be expressed as

$$
F^{(z)}=\frac{\rho_{0} a}{N^{2} H} \sum_{s} \frac{1}{2} \operatorname{Re}\left[i s \frac{\partial \Phi_{s}}{\partial \zeta} \Phi_{s}^{*}\right]
$$

after some manipulation, where $*$ denotes the complex conjugate, and $\Phi^{\prime}=\operatorname{Re} \sum_{s} \Phi_{s} \exp (i s \lambda)$. Then meridionally averaged and time-integrated $F^{(z)}$ can be expanded by Hough modes;

$$
\begin{aligned}
& \int_{-\infty}^{\infty} \int_{-\pi / 2}^{\pi / 2} \frac{F^{(z)}}{2 \rho_{0} a H} \cos \varphi d \varphi d t \\
= & \frac{2 \pi e^{\zeta}}{N^{2} H^{2}} \sum_{s, n} \int_{-\infty}^{\infty} \frac{1}{2} \operatorname{Re}\left[i s \mathcal{T}_{s n}^{\omega}(\zeta) \mathcal{U}_{s n}^{\omega}(\zeta)^{*}\right] d \omega \\
\equiv & \mathcal{F}_{s n}^{\omega}(\zeta)
\end{aligned}
$$

Since we assume the Newtonian cooling, Eq. (23) does not strictly hold. However, it is confirmed that there is little difference between $F^{(z)}$ calculated directly from Eq. (22) and its approximation Eq. (23) above the forcing region. Therefore, we use Eq. (23) as the vertical component of the EP flux and $\mathcal{F}_{s n}^{\omega}(\zeta)$ of Eq. (24) as the zonal momentum flux of each Hough mode.

Figure 16 shows $\mathcal{F}_{i}$ for each kind of wave at $\zeta=2$ as a function of zonal wavenumber $s$. Kelvin waves, inertio-gravity waves and eastward propagating Rossby-gravity waves carry most of the zonal momentum in the experiment (A), while Kelvin waves and Rossby waves are dominant in the experiment (D). In both cases, waves of sufficiently small wavenumbers have a small amount of momentum flux because of the factor $s$ in Eq. (23). This factor makes the wavenumber spectrum of zonal momentum flux wide to higher zonal wavenumbers than the energy spectrum.

Figure 17 shows $\left|\mathcal{F}_{i}\right|$ for six kinds of wave in twelve experiments (A) $-(\mathrm{F})$ and $(\mathrm{G})-(\mathrm{L})$. Here, inertiogravity waves and Rossby-gravity waves are divided into a westward component (W) and an eastward component (E). Waves of $h<0$ are not shown in the figure because they are vertically evanescent. The values at three levels are denoted by three different lines; solid line with $\mathrm{L}$ : $\zeta=2$, dashed line with $\mathrm{M}$ : $\zeta=4.5$, and dotted line with $\mathrm{H}: \zeta=7$. For shortlived heating with $T=0.1$ days $(\mathrm{A}, \mathrm{B}, \mathrm{G}, \mathrm{H})$, each of $\left|\mathcal{F}_{i}\right|$ carried by Kelvin, westward and eastward inertio-gravity, and eastward Rossby-gravity waves is roughly comparable, while $\left|\mathcal{F}_{i}\right|$ for long-lived heating $(\mathrm{E}, \mathrm{F}, \mathrm{K}, \mathrm{L})$ is mainly carried by Kelvin, westward Rossby-gravity, and Rossby waves (Note that Rossby-gravity waves are not excited in $\mathrm{G}-\mathrm{L}$ ). The vertical increase of $\left|\mathcal{F}_{i}\right|$ due to the density effect is approximately compensated by the dissipation effect when $T=0.5$ days $(\mathrm{C}, \mathrm{D}, \mathrm{I}, \mathrm{J})$; the zonal momentum flux increases with height for $T=0.1$ days (A, $\mathrm{B}, \mathrm{G}, \mathrm{H}$ ), while it decreases with height for $T=1.5$ days $(\mathrm{E}, \mathrm{F}, \mathrm{K}, \mathrm{L})$.

\section{Discussion}

a. Assessment of linearity by a nonlinear timeintegration model

Prior to the detailed linear analyses stated in the previous sections, time-integrations of the full nonlinear equations were done to assess the linearity of the response. The model has T21 truncation, vertical resolution of about $1.5 \mathrm{~km}$, and the Newtonian cooling is incorporated. The same experiments as in Section 4 were done with different values of $J_{0} / C_{p}$, $20 \mathrm{~K} /$ day and $1 \mathrm{~K} /$ day; the former is a typical value of the heating observed in a cloud cluster (e.g., Johnson, 1992). Responses for $J_{0} / C_{p}=20 \mathrm{~K} /$ day were nearly the same as those with $J_{0} / C_{p}=1 \mathrm{~K} /$ day except that the magnitude of the former was 20 

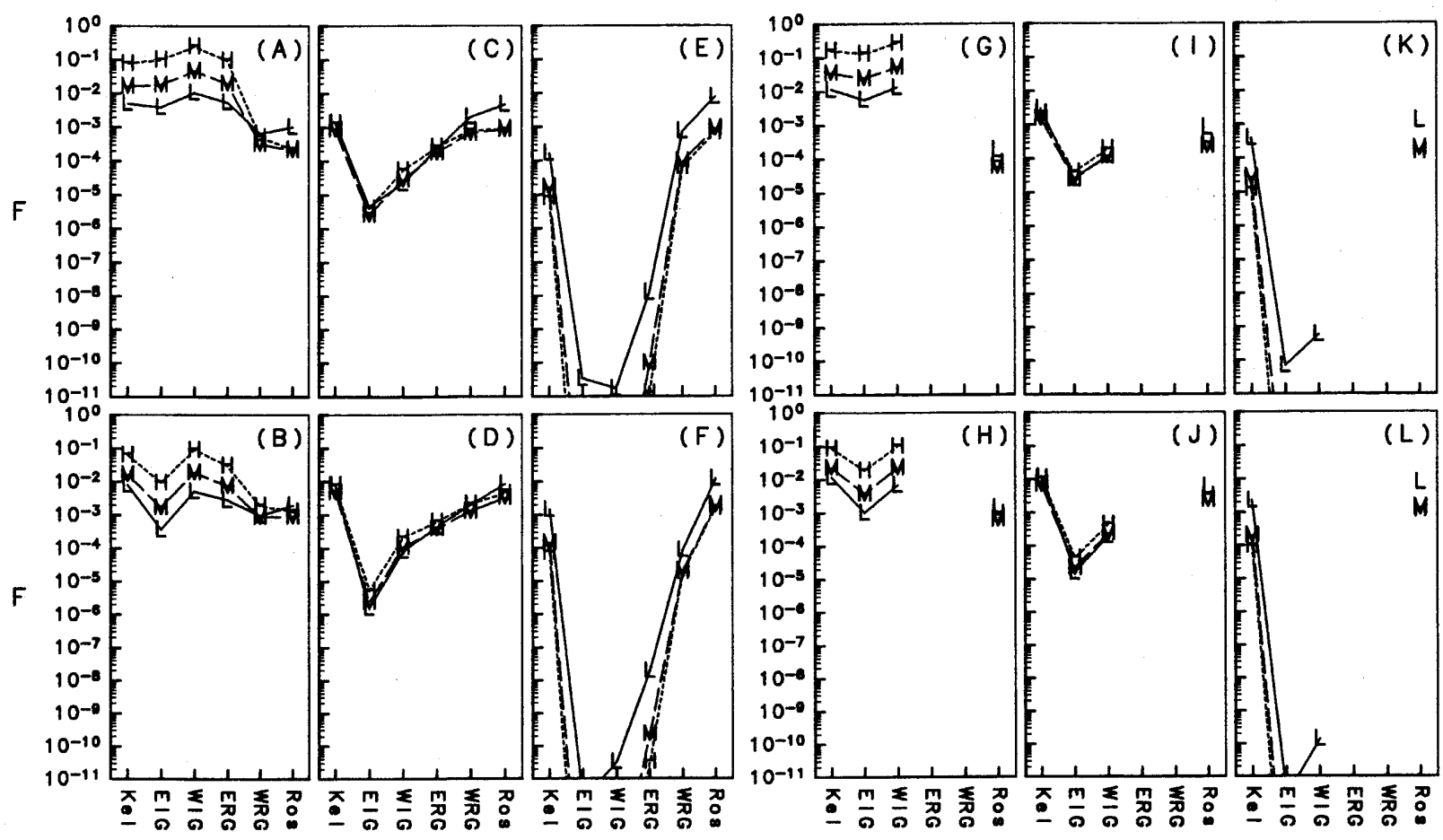

Fig. 17. $\left(3 J_{s} / J_{0}\right)\left|\mathcal{F}_{i}\right|\left[\mathrm{ms}^{-1}\right.$ day $\left.^{-1}\right]$ of each kind of wave in twelve experiments $(\mathrm{A})-(\mathrm{F})$ and $(\mathrm{G})-(\mathrm{L})$ at $\zeta=2$ (solid line with symbol "L"), at $\zeta=4.5$ (dashed line with symbol "M"), and at $\zeta=7$ (doted line with symbol "H"). Here, $3 J_{s} / J_{0}\left[\right.$ day $\left.^{-1}\right]\left(J_{s} \equiv 20 \mathrm{~K} /\right.$ day $)$ is a weight for the transformation to estimate the time-averaged $\left|\mathcal{F}_{i}\right|$ produced by a stochastic random heating process with a realistic total amount of heating (see Section 5 for details). Inertio-gravity (IG) and Rossby-gravity (RG) waves are divided into westward component (W) and eastward component $(\mathrm{E})$, respectively.

times that of the latter. A convectively unstable region of $d \theta / d \zeta<0$, where $\theta$ is potential temperature, was not observed even in the experiments with $J_{0} / C_{p}=20 \mathrm{~K} /$ day. Thus we can conclude that the response to the heating with realistic amplitude is almost linear. In addition, time evolutions of flow field obtained by the nonlinear model were similar to those in the present linear calculations, although the latter resolved even finer scales. Furthermore, numerical experiments with an initial condition of some zonally symmetric climatological states showed that the responses of the climatological basic states are not drastically different from those of the resting basic state but are some modifications of them (we will investigate the effect of the climatological basic states in a future paper). These results enable us to analyze the wave excitation by localized transient heating with a linear model used in this paper.

\section{b. Vertical wavelengths of dominant vertically prop- agating waves}

In the equatorial lower stratosphere, a typical vertical wavelength of observed Kelvin waves is about $10 \mathrm{~km}$, that of Rossby-gravity waves is $5 \sim 6 \mathrm{~km}$ (Wallace, 1973), and that of inertio-gravity waves is even smaller (e.g., Tsuda et al., 1994). However, the dominant wavelength of vertically propagating waves in this paper is about 2 scale heights $(14 \mathrm{~km})$ in the lower part of the middle atmosphere.

This discrepancy might be attributed to realistic vertical structures of heating and basic state temperature which might be different from those used in this paper. Observed mature cloud clusters show considerable heating in the upper and middle troposphere, but convective heating in the lower troposphere tends to be compensated by the evaporation of falling rain. Then we calculated the solution of the vertical structure equations with the heating term $e^{\zeta / 2} \mathcal{J}=1$ for $0.5<\zeta<1.5$ and $\mathcal{J}=0$ elsewhere. The response around $h \sim 200 \mathrm{~m}$ was still dominant, although its higher harmonics increased; the principal response was larger than the harmonics by about one order. This result is consistent with the finding by SG that the response is not sensitive to the vertical profile of the heating but sensitive to the depth of the heating.

The thermal structure of the present basic state which has the tropopause at $12 \mathrm{~km}$ may not be realistic in the tropics. However, even if we assume a higher and colder tropopause, the dominant vertical wavelength of the response in the middle atmosphere is unchanged unless the buoyancy frequencies in the troposphere and/or the middle atmosphere 
Table 1. Parameters of heating. The other parameters $\lambda_{0}$ and $t_{0}$ are fixed to $\pi$ and 0 , respectively.

\begin{tabular}{l|rrrcl}
\hline & $\varphi_{0}\left[{ }^{\circ}\right]$ & $\Lambda\left[^{\circ}\right]$ & $\Phi\left[^{\circ}\right]$ & $T[$ day $]$ & $J_{0} / C_{p}[\mathrm{~K} /$ day $]$ \\
\hline \hline & & & & & \\
$(\mathrm{A})$ & 10 & 3 & 3 & 0.1 & $5.56 \times 10^{2}$ \\
$(\mathrm{~B})$ & 10 & 10 & 10 & 0.1 & $5.00 \times 10^{1}$ \\
$(\mathrm{C})$ & 10 & 3 & 3 & 0.5 & $1.11 \times 10^{2}$ \\
$(\mathrm{D})$ & 10 & 10 & 10 & 0.5 & $1.00 \times 10^{1}$ \\
$(\mathrm{E})$ & 10 & 3 & 3 & 1.5 & $3.70 \times 10^{1}$ \\
$(\mathrm{~F})$ & 10 & 10 & 10 & 1.5 & 3.33 \\
& & & & & \\
$(\mathrm{G})$ & 0 & 3 & 3 & 0.1 & $5.56 \times 10^{2}$ \\
$(\mathrm{H})$ & 0 & 10 & 10 & 0.1 & $5.00 \times 10^{1}$ \\
$(\mathrm{I})$ & 0 & 3 & 3 & 0.5 & $1.11 \times 10^{2}$ \\
$(\mathrm{~J})$ & 0 & 10 & 10 & 0.5 & $1.00 \times 10^{1}$ \\
$(\mathrm{~K})$ & 0 & 3 & 3 & 1.5 & $3.70 \times 10^{1}$ \\
$(\mathrm{~L})$ & 0 & 10 & 10 & 1.5 & 3.33 \\
& & & & & \\
\hline
\end{tabular}

are changed. This is because the dominant vertical wavelength in the middle atmosphere is basically determined by the ratio of the buoyancy frequencies as well as the depth of the heating. The change of the tropopause height may affect the partial reflection of propagating waves at this level, but the effect on the dominant vertical wavelength is not significant.

Discussion above suggests that neither the realistic vertical structure of heating nor that of the basic state can explain the observed small vertical wavelengths of Rossby-gravity and inertio-gravity waves. A possible reason for the small vertical wavelengths is the effect of vertical shear of mean zonal wind $\bar{u}$ in the real middle atmosphere. If $\partial \bar{u} / \partial z$ is positive (negative), the vertical wavelengths of eastward(westward-) propagating waves are reduced during the vertical propagation. This is explained by a WKB theory of vertically propagating waves; the vertical wavelength changes according to the change of the intrinsic frequency. At the same time as this reduction, the amplitude of horizontal wind perturbation is increased (Lindzen, 1971), and thus these waves can readily be detected by observation. Hence, dominant vertical wavelengths in observations may be biased toward small values owing to the vertical shear. Note that the typical vertical wavelengths mentioned above were estimated from observations in a particular QBO phase favored by this effect (Wallace and Kousky, 1968b; Shiotani and Horinouchi, 1993). This effect can explain the observed vertical wavelengths of Kelvin waves which are slightly smaller than $14 \mathrm{~km}$ in the lower stratosphere.

Another possible reason is in the heating itself: the spectrum of actual heating is neither white nor Gaussian. Cumulus convections dynamically inter- act with the environmental large-scale field to organize themselves in the large-scale field. For example, Takayabu (1994) found that cloud systems over the equatorial western Pacific and Maritime continent are organized according to the dispersion relation of equatorial waves of $h=15 \sim 30 \mathrm{~m}$. Waves of $h=20 \mathrm{~m}$, for example, have a vertical wavelength of about $4 \mathrm{~km}$ in the middle atmosphere. Therefore, observed small vertical wavelengths of equatorial waves may be a result of such interaction between cumulus convections and large-scale dynamics.

c. Order estimation of wave energy and momentum by a stochastic heating process and comparison with observations

Total heating of each experiment in Section 4 is about $1 / 3$ of the annually averaged value per day estimated from the observed precipitation in the equatorial region. Here we suppose a stochastic random heating process in which the total heating per day is equal to the annual average. If we also assume individual heating events of this process are the form of Eqs. (16) and (19) with a fixed amplitude of $J_{s} \equiv 20 \mathrm{~K} /$ day, and randomly determined $\lambda_{0}$ and $t_{0}$, the heating events occur $3 \times J_{0} / J_{s}$ times per day, where $J_{0}$ is the value listed in Table 1 . For example, 83 events occur per day in the random heating process for the parameter value of (A). Then the time-averaged energy of the $i$-th kind of wave of the response to such a heating process is $3 \times J_{s} /\left(8.64 \times 10^{4} \times J_{0}\right)\left[\mathrm{s}^{-1}\right]$ times as large as the time-integrated value of $\overline{E_{i}}\left[\mathrm{~m}^{2} \mathrm{~s}^{-1}\right]$ given in Section 4 , if the response is linear. Table 2 shows the time-averaged wave energy for (A)-(L) at the level of $\zeta=2$. While $\overline{E_{i}}$ is a globally averaged value, most of the energy of vertically propagating waves is confined near the equator. Thus the listed value is less than the energy averaged in low latitudes. In addition, $\alpha=1 / 7$ day $^{-1}$ is larger than realistic values for the lower stratosphere and troposphere; if $\alpha$ is decreased in these layers, the energy of the responses should increase. This increase will be noticeable for waves of $\omega \leq \alpha$, since such low-frequency waves suffer much dissipation, as shown in Section 3. We should compare the values in Table 2 with observations, keeping these factors in mind.

Kelvin waves at $\zeta=2$, of which the energy is dependent on the horizontal scale of the heating but is insensitive to the choice of $T$, have a comparable order to the observations in the experiments with $\Lambda=\Phi=10^{\circ}$, particularly when the heating is placed on the equator $\left(\varphi_{0}=0^{\circ}\right)$. They are smaller by 1 order or more when $\Lambda=\Phi=3^{\circ}$. When $T=0.1$ days or 0.5 days, the time-averaged energy for Rossby-gravity waves is of a comparable order to the observations; they consist mainly of eastwardpropagating waves for $T=0.1$ days while westward- 
Table 2. Horizontally- and time-averaged wave the energy at $\zeta=2$ for the stochastic random heating processes with a realistic total amount of heating. Unit is $\mathrm{m}^{2} \mathrm{~s}^{-2}$. (See text for details.)

\begin{tabular}{|c|c|c|c|c|c|}
\hline & Kelvin & Inertio-gravity & Rossby-gravity & Rossby & $h<0$ \\
\hline (A) & $3.05 \times 10^{-1}$ & 1.57 & $9.01 \times 10^{-1}$ & $3.65 \times 10^{-1}$ & $1.08 \times 10^{-1}$ \\
\hline (B) & $8.94 \times 10^{-1}$ & 1.23 & 1.25 & $5.80 \times 10^{-1}$ & $1.25 \times 10^{-1}$ \\
\hline (C) & $2.30 \times 10^{-1}$ & $7.85 \times 10^{-3}$ & 1.44 & 1.70 & $4.82 \times 10^{-1}$ \\
\hline (D) & 1.53 & $3.07 \times 10^{-2}$ & 1.45 & 2.61 & $4.91 \times 10^{-1}$ \\
\hline (E) & $8.24 \times 10^{-2}$ & $8.17 \times 10^{-8}$ & $6.79 \times 10^{-1}$ & 3.33 & $8.32 \times 10^{-1}$ \\
\hline (F) & $7.34 \times 10^{-1}$ & $3.47 \times 10^{-8}$ & $4.96 \times 10^{-2}$ & 4.94 & $8.86 \times 10^{-1}$ \\
\hline (G) & $6.66 \times 10^{-1}$ & 2.15 & 0 & $6.13 \times 10^{-2}$ & $1.81 \times 10^{-2}$ \\
\hline (H) & 1.33 & 1.95 & 0 & $4.03 \times 10^{-1}$ & $1.00 \times 10^{-1}$ \\
\hline (I) & $5.10 \times 10^{-1}$ & $5.92 \times 10^{-2}$ & 0 & $1.17 \times 10^{-1}$ & $1.27 \times 10^{-2}$ \\
\hline (J) & 2.35 & $9.77 \times 10^{-2}$ & 0 & 1.81 & $3.98 \times 10^{-1}$ \\
\hline (K) & $2.17 \times 10^{-1}$ & $7.19 \times 10^{-7}$ & 0 & $5.34 \times 10^{-1}$ & $1.69 \times 10^{-1}$ \\
\hline (L) & 1.20 & $1.80 \times 10^{-7}$ & 0 & 3.25 & $6.94 \times 10^{-1}$ \\
\hline
\end{tabular}

propagating waves for $T=0.5$ days. They are small one order or more when $T=1.5$ days. Inertiogravity waves for $T=0.5$ days and 1.5 days are obviously too small, while those for $T=0.1$ days seem to be close to those in the real atmosphere, although a typical value of the energy of inertiogravity waves in the equatorial middle atmosphere is not well known. The present estimation suggests that energy of various vertically propagating waves may have a realistic order if we consider a random heating process which consists of various types of heating events as in Table 2 with an appropriate ratio and realistic total amount of the heating.

Rossby waves in the upper part of the middle atmosphere consist mainly of normal modes. The energy of Rossby waves at $\zeta=4.5(\sim 10 \mathrm{hPa})$ is largest in Experiment (D) $\left(\overline{E_{i}}=0.886 \mathrm{~m}^{2} \mathrm{~s}^{-2}\right)$, and the contribution of the gravest symmetric Rossby mode of $s=1$, "5-day wave", is $0.12 \mathrm{~m}^{2} \mathrm{~s}^{-2}$. On the other hand, the observed amplitude of geopotential height perturbation of the 5 -day wave is about $30 \mathrm{~m}$ at $40^{\circ} \mathrm{N}$ and $10 \mathrm{hPa}$ when the wave is prominent (Hirota and Hirooka, 1984), which amplitude corresponds to the energy of $0.7 \mathrm{~m}^{2} \mathrm{~s}^{-2}$. The excitation of the 5-day wave in Experiment (D) seems to be of a comparable order to that in the real atmosphere, because the observational amplitude referred above is an extreme value and is not always observed. As for other experiments $(\mathrm{A})-(\mathrm{F})$, the 5 -day wave in $(\mathrm{F})$ is comparable to (D) while that in (A), (B), (C), and (E) (i.e., $T=0.1$ days or $\Lambda=\Phi=3^{\circ}$ ) are much smaller than (D).

A similar discussion can be held on the vertical flux of zonal momentum; we can evaluate the flux as a time average in units of $\mathrm{ms}^{-1} \mathrm{day}^{-1}$ by multiplying $\mathcal{F}\left[\mathrm{ms}^{-1}\right]$ of Eq. $(24)$ by $3 \times J_{s} / J_{0}\left[\right.$ day $\left.^{-1}\right]$. If we assume that there is no "residual circulation" and that the zonal wind above a level $\zeta_{1}$ is accelerated rigidly over the whole globe, then the zonal wind acceleration above $\zeta_{1}$ on the equator will be equal to the same values as in Fig. 17. Some values in Fig. 17 are of the order of $10^{-1} \mathrm{~ms}^{-1} \mathrm{day}^{-1}$ while others are of much smaller orders. If we note that the zonal wind acceleration of the quasi-biennial oscillation (QBO) in the equatorial lower stratosphere is about $0.3 \mathrm{~ms}^{-1} \mathrm{day}^{-1}$ on the equator, which corresponds to a globally averaged value of $\mathcal{F} \sim 0.03 \mathrm{~ms}^{-1} \mathrm{day}^{-1}$, then we can say that the vertical flux in the experiments of $T=0.1$ days (A, B, G, H) has comparable order to that necessary for producing the zonal wind acceleration of the QBO.

\section{d. Comments on the past studies}

Based on the present study we comment on some past studies which investigated the response to localized transient heating.

Holton (1972) showed that localized oscillating thermal forcing can excite equatorial waves. Figure 9 of his paper shows that Rossby-gravity waves of zonal wavenumber $s \simeq 4$ and vertical wavelength about $7 \mathrm{~km}$ are dominant in the lower stratosphere for forcing that is sinusoidally periodic with a period of 5 days and is antisymmetric about the equator. This figure is used in a standard textbook Andrews et al. (1987; Fig. 4.26). However, this result seems to have suffered a strong truncation error. He truncated at $s=5$ in the calculation. Rossby-gravity waves with a period of 5 days has the equivalent depth $h=30 \mathrm{~m}$ for $s=4$, and $h=50 \mathrm{~m}$ for $s=5$. These values are consistent with the obtained vertical wavelength. However, waves of such values of $h$ are less effectively excited than those of $h \sim 200 \mathrm{~m}$. Thus, if he had truncated at $s \leq 8$, Rossby-gravity waves of $s \sim 8$ which have $h \sim 200 \mathrm{~m}$ would have dominated in the response. 


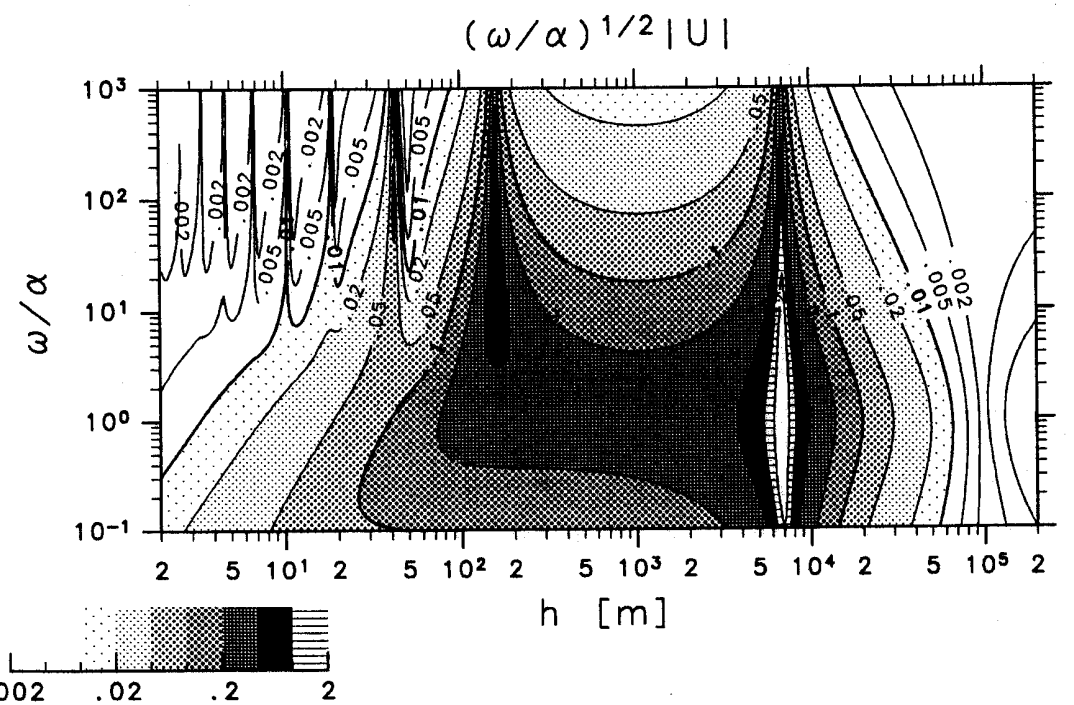

Fig. 18. As in Fig. 4a but the buoyancy frequency $N$ of the middle atmosphere is 1000 times as large as that in the troposphere.

Hayashi (1976) showed that the dominant vertically propagating responses to oscillating thermal forcing have vertical velocities not in phase with the heating but lagged by about $\pi / 2$ in the forcing region, whereas observations show that they are almost in phase. Thus he concluded that observed waves cannot be regarded as the response to the thermal forcing. However, the present calculations show that obtained vertical velocity in the forcing region is nearly in phase with the heating consistent with the observations. This is because of the piled effect of responses which are mainly confined in the troposphere (waves of $h<200 \mathrm{~m}$ ). This effect was first pointed out by Itoh (1977).

$\mathrm{MH}$ showed that global normal modes obtained in their linear model with convective heating are much smaller than those in the SKIHI GCM, while SG emphasized their excitation by such heating without quantitative estimations. The present calculation showed that some stochastic heating process with appropriate heating parameters can excite global normal modes comparable to their observational magnitude. However, we cannot conclude from this result that the normal modes in the real atmosphere are excited by convective heating, since such freely traveling waves with global coverage may be excited by various causes; $\mathrm{MH}$ showed that the main source of the normal modes in their GCM was anything but convective heating.

\section{e. Effect of the rigid lid approximation at the tropo pause}

At the upper boundary we assumed the radiation condition that allows the wave energy to propagate upward in order to study the response in the middle atmosphere. In some studies focusing on the tropospheric response, on the other hand, a rigid lid is placed at the tropopause, and a free slip boundary condition is used there. Furthermore, only a baroclinic vertical eigenmode between the upper and lower boundaries is investigated in some of these studies; Gill (1980) studied steady response to steady heating in the tropics, while Silva Dias et al. (1983) studied response to transient heating in the tropics with time scales from a few hours to a day.

Figure 18 shows $\tilde{\omega}^{1 / 2}|\mathcal{U}|$ at $\zeta=0.1$ for the same heating as that in Fig. 4 but with $N$ in the middle atmosphere being 1000 times as large as that of the troposphere. Note that the limit of $N \rightarrow \infty$ corresponds to placing a free-slip rigid lid at the tropopause. The difference between Fig. 18 and Fig. 4a is quite small for $\tilde{\omega}<1$, while it is large for $\tilde{\omega}>10$ and $h<1000 \mathrm{~m}$. In the invisid limit (i.e. $\tilde{\omega} \rightarrow \infty$ ), the rigid boundaries at the top and the bottom allow "stationary" waves at discrete $h \mathrm{~s}$, at which waves are resonantly excited by heating if $\tilde{\omega}>10$. That is, responses of which the frequency is much larger than the damping rate feel the lid at the tropopause and their long-time behavior is affected by the reflection at the lid. Though the basic state for Fig. 4 also has an increase of $N$ at the tropopause, it cannot be regarded as a lid even for the frequency range $\tilde{\omega}>10$.

Therefore, the steady responses studied by Gill (1980) suffer little effect of the lid that confines the energy in the troposphere. However, the transient responses studied by Silva Dias et al. (1983) suffer the effect considerably. Thus transient time evolutions obtained under the rigid approximation are appropriate only for a short period immediately after the onset of the heating and before the excited waves interact with the lid. 


\section{f. Suggestion for further studies}

The heating assumed in this paper does not move. However, typical cloud clusters move westward while super cloud clusters move eastward (Nakazawa, 1988). Thus it is worthwhile to calculate how the distributions of energy and momentum are changed when the heating moves zonally in the present framework. Moreover, further investigations with nonlinear models which include various cumulus parameterizations would be required to confirm the interaction between cumulus convections and large-scale flow field including equatorial waves which propagate vertically into the middle atmosphere, although MH's results suggest that there is little feedback of large-scale dynamics to the moist convective adjustment in their GCM.

\section{Conclusions}

Linear response of a resting spherical atmosphere to localized heating in the tropical troposphere was investigated with linearized primitive equations. The method of separation of variables was used to solve the problem; the response was calculated by Hough space-time transformation, which enables us to discuss the response by separating it into each type of wave such as Kelvin, Rossby, Rossby-gravity, and inertio-gravity waves.

We assessed the linearity using a nonlinear primitive model. The linearity of the response is good for some realistic values of the heating.

The basic feature of the excitation of these waves is well understood through the examination of the vertical structure equation with some consideration of the dispersion relation of Hough functions. The dominant responses are equatorially trapped and vertically propagating waves of the equivalent depth $h \sim 200 \mathrm{~m}$, and global normal (or free) modes of $h \sim 10 \mathrm{~km}$ (similar to SG). In the stochastic sense in which time-integrated properties are focused, the vertically propagating waves have large response in the middle atmosphere if the angular frequency is the order of $10 \times$ [damping rate]. This frequency of large response increases with height, since low-frequency waves dissipate effectively in the lower region. On the other hand, horizontal-scale selection of waves is not simple. If the horizontal scale of Rossby waves is sufficiently smaller than the radius of deformation, they are not favorably excited. This is a similar situation to the geostrophic adjustment in a shallow water system. However, the difference in frequencies between gravity waves and Rossby waves can cause the opposite selection; Rossby waves are favorably excited compared with gravity waves.

The spatial pattern of the response is obtained for a realization of idealized stochastic heating with a Gaussian form in space and time. For the heating of which the time scale is a few days or longer, hor- izontal cross sections of the response show the "Gill pattern" at the beginning and then the response disperses zonally in low latitudes. For short-lived heating of which the time scale is less than a day, on the other hand, the gravity wave response expands concentrically at the beginning and then the response spreads zonally in low latitudes.

The method of separation of variables enables us to study energy and momentum flux distributions to various kinds of wave. Qualitative argument on the wave selection with the vertical structure equation is confirmed by numerical calculations for some parameter ranges of the heating. As the time scale of the heating events decreases (or, as the frequency spectrum of the heating approaches white one), gravity-wave responses increase relatively to Rossby-wave responses. As the zonal scale of the heating events decreases (or, as the zonal spectrum of the heating approaches white one), on the other hand, Rossby-wave responses slightly increase relative to gravity-wave responses. Meridional scale and meridional position of the heating control the response mainly through the projection of the heating onto Hough functions; heating just on the equator is less effective in exciting Rossby waves than that off the equator, while it is effective for gravity waves. Energy and momentum flux of vertically propagating waves have comparable orders to those of the real atmosphere if the heating has some appropriate spectrum with a realistic magnitude comparable to the total latent heat release in the tropics; and so does the energy of global normal modes.

Some studies focusing on the tropospheric response to localized heating have placed a rigid lid at the top boundary and investigated a baroclinic vertical mode between the rigid upper and lower boundaries. However, the present calculation shows that wave propagation into the middle atmosphere has to be taken into account, even for the calculation of the transient response in the troposphere, if the dominant frequency of the response is larger than the damping rate.

\section{Acknowledgments}

The authors wish to thank Dr. K. Ishioka who offered the FORTRAN program to calculate Hough functions. They also wish to thank Drs. Y. Hayashi and $\mathrm{H}$. Itoh for their helpful discussions and comments on this work. The GFD-DENNOU Library was used for drawing figures and nonlinear timeintegrations. Numerical calculation was done on the KDK system at RASC, Kyoto University. This work was supported in part by the Grant-in-Aid for Scientific Research, the Ministry of Education, Science, and Culture of Japan, and by the Grant-in-Aid for the Cooperative Research with Center for Climate System Research, University of Tokyo. 


\section{References}

Andrews, D.G., J.R. Holton and C.B. Leovy, 1987: Middle Atmosphere Dynamics. Academic Press 489 pp.

Bergman, J.W. and M.L. Salby, 1994: Equatorial wave activity derived from fluctuations in observed convection. J. Atmos. Sci., 51, 3791-3806.

Chang, C.P., 1977: Viscous internal gravity waves and low-frequency oscillations in the tropics. J. Atmos. Sci., 34, 901-910.

Garcia, R.R. and M.L. Salby, 1987: Transient response to localized episodic heating in the tropics. Part II: Far field behavior. J. Atmos. Sci., 44, 499-530.

Gill, A.E., 1980: Some simple solutions for heat-induced tropical circulation. Quart. J. Roy. Meteor. Soc., 106, 447-462.

Hayashi, Y., 1970: A theory of large-scale equatorial waves generated by condensation heat and accelerating the zonal wind. J. Meteor. Soc. Japan, 48, 140-160.

Hayashi, Y., 1976: Non-singular resonance of equatorial waves under the radiation condition. J. Atmos. Sci., 33, 183-201.

Hayashi, Y. and D.G. Golder, 1978: The generation of equatorial transient planetary waves: control experiments with a GFDL general circulation model. $J$. Atmos. Sci., 35, 2068-2082.

Hirota, I., 1978: Equatorial waves in the upper stratosphere and mesosphere in relation to the semiannual oscillation of the zonal wind. J. Atmos. Sci., 39, 714-722.

Hirota, I. and T. Hirooka, 1984: Normal mode Rossby waves observed in the upper stratosphere. Part I: First symmetric modes of zonal wavenumbers 1 and 2. J. Atmos. Sci., 41, 1253-1267.

Holton, J.R., 1972: Waves in the equatorial stratosphere generated by tropospheric heat sources. J. Atmos. Sci., 29, 368-375.

Holton, J.R., 1973: On the frequency distribution of atmospheric Kelvin waves. J. Atmos. Sci., 30, 499 501.

Itoh, H., 1977: The response of equatorial waves to thermal forcing. J. Meteor. Soc. Japan, 55, 222-239.

Johnson, R.H., 1992: Heat and moisture sources and sinks of Asian monsoon precipitating systems. $J$. Meteor. Soc. Japan, 70, 353-372.

Lindzen, R.S., 1971: Equatorial Planetary waves in shear: Part I. J. Atmos. Sci., 28, 609-622.

Longuet-Higgins, M.S., 1968: The eigenfunctions of Laplace's tidal equations over a sphere. Philos. Trans. R. Soc. London. Ser., A262, 511-607.

Mak, M.K., 1969: Laterally driven stochastic motions in the tropics. J. Atmos. Sci., 26, 41-64.

Magaña, V. and M. Yanai, 1991: Tropical-midlatitude interaction on the time scale of 30 to 60 days during the northern summer of 1979 . J. Climate, 4, 180201.

Magaña, V. and M. Yanai, 1995: Mixed Rossby-gravity waves triggered by lateral forcing. J. Atmos. Sci., 52, 1473-1486.

Manzini, E. and K. Hamilton, 1993: Middle atmospheric traveling waves forced by latent and convective heating. J. Atmos. Sci., 50, 2180-2200.

Nakazawa, T., 1988: Tropical super clusters within intraseasonal variation over the western Pacific. J. Meteor. Soc. Japan, 66, 823-839.

Salby, M.L. and R.R. Garcia, 1987: Transient response to localized episodic heating in the tropics. Part I: Excitation and short-time near field behavior. J. Atmos. Sci., 44, 458-498.

Silva Dias, P.L. and W.H. Schubert and M. DeMaia, 1983: Large-scale response of the tropical atmosphere to transient convection. J. Atmos. Sci., 40, 2689-2707.

Shiotani, M. and T. Horinouchi, 1993: Kelvin wave activity and the quasi-biennial oscillation in the equatorial lower stratosphere. J. Meteor. Soc. Japan, 71, 175-182.

Takayabu, Y.N., 1994: Large-scale cloud disturbances associated with equatorial waves. Part I: Spectral features of the cloud disturbances. J. Meteor. Soc. Japan, 72, 433-449.

Tsuda, T., Y. Maruyama, H. Wiryosumarto, S.W.B. Harijono and S. Kato, 1994: Radiosonde observations of equatorial atmosphere dynamics over Indonesia 2. Characteristics of gravity waves. $J$. Geophys. Res., 99, 10, 507-10, 516.

Wallace, J.M., 1973: General circulation of the tropical lower stratosphere. Rev. Geophys. Space Phys., 11, 191-222.

Wallace, J.M. and V.E. Kousky, 1968a: Observational evidence of Kelvin waves in the tropical stratosphere. J. Atmos. Sci., 25, 900-907.

Wallace, J.M. and V.E. Kousky, 1968b: On the relation between Kelvin waves and the quasi-biennial oscillation. J. Meteor. Soc. Japan, 46, 496-502.

Yanai, M. and M.M. Lu, 1983: Equatorially trapped waves at the $200 \mathrm{mb}$ level and their association with meridional convergence of wave energy flux. $J$. Atmos. Sci., 40, 2785-2803.

Yanai, M. and T. Maruyama, 1966: Stratospheric wave disturbances propagating over the equatorial Pacific. J. Meteor. Soc. Japan, 44, 291-294.

Zangvil, A. and M. Yanai, 1980: Upper tropospheric waves in the tropics. Part I: Dynamical analysis in the wavenumber-frequency domain. J. Atmos. Sci., 37, 283-298. 


\section{熱帯に局在した加熱による波動励起と中層大気への伝播 \\ 堀之内武・余田成男 \\ (京都大学理学部地球物理学教室)}

熱帯に局在した非定常な加熱に対する球面上の静止大気の応答を、線形化したプリミティブ方程式系を 用いて理論的に調べた。変数分離法で問題を解く一方で、線形性を評価するために非線形方程式の時間積 分も行なった。

現実的な強さの加熱に対する応答の線形性は良い。卓越する応答は、赤道域に捕捉され鉛直スケールが 加熱のそれにあった鉛直伝播性の波動と、全球的なノーマル(自由)モードである。赤道域に捕捉された波 動は、中層大気中では角振動数が $10 \times$ [散逸の時間スケール] ${ }^{-1}$ のオーダーのものが効果的に応答をする。 振動数がこれより大きい場合確率論的に見れば応答が抑制される。また振動数がこれより小さい場合も散 逸のために応答が抑制される。

理想化した確率論的な加熱過程の一試行として、時空間にガウス型をした加熱に対する応答の空間パ夕 ーンを調べた。加熱の時間スケールが数日以上の場合には、応答の水平断面は初期に「ギルパターン」を 示し、やがて低緯度域で東西に広がる。一方、短い時間スケールの加熱の場合には、重力波が同心円的に 広がり、やがてやはり低緯度域で東西に応答が広がる。

確率論的な加熱過程により励起される、いくつかの種類の波動のエネルギーと運動量のスペクトルを計 算した。加熱の時間スケールが短くなると重力波がロスビー波に比べて相対的に増加する。一方、加熱の 東西スケールが小さくなるとロスビー波が重力波に比べて少し増加する。加熱のスペクトル形をうまく与 えれば、現実的な熱帯の潜熱放出総量に相当する範囲内で観測される鉛直伝播性波動のエネルギーや運動 量をオーダー的に再現し得る。ノーマルモードのエネルギーについても同様である。

卓越する振動数が散逸率より大きい非定常な応答を求めるときには、対流圈に着目する場合でも波の工 ネルギーが中層大気に抜けていくということを考慮に入れる必要があることがわかった。 